\title{
A comparative study of melilite and fassaite in Types B1 and B2 refractory inclusions
}

\author{
S.B. Simon ${ }^{\mathrm{a}, *}$, L. Grossman ${ }^{\mathrm{a}, \mathrm{b}}$ \\ ${ }^{\text {a }}$ Department of the Geophysical Sciences, 5734 S. Ellis Ave., The University of Chicago, Chicago, IL 60637, USA \\ ${ }^{\mathrm{b}}$ The Enrico Fermi Institute, 5640 S. Ellis Ave., The University of Chicago, Chicago, IL 60637, USA
}

Received 26 April 2005; accepted in revised form 23 September 2005

\begin{abstract}
Most of the petrologic data available for Type B inclusions comes from Type B1s. Relatively little comes from the B2s, and there has not been a systematic comparison of the properties of their two most abundant minerals. In this work, we document the compositions and zoning patterns of melilite and fassaite in Type B2 inclusions, and compare and contrast them with the features of their counterparts in Type B1 inclusions. We find that melilite compositions in Type B2 inclusions are similar to those of Type B1s, with maximum $\AA \mathrm{k}$ contents of $\sim 75 \mathrm{~mol} \%$ and a positive correlation between $\AA \mathrm{k}$ and $\mathrm{Na}_{2} \mathrm{O}$ contents. Asymmetrically zoned melilite is common in Type B2s as are melilite grains with reversely zoned regions, and the reversely zoned portions of crystals are thicker than in B1s. In B2s, like $\mathrm{B} 1 \mathrm{~s}$, fassaite is zoned with decreasing $\mathrm{Ti}, \mathrm{Sc}$, and $\mathrm{V}$ oxide contents from cores to rims of grains. Approximately half of the Ti is trivalent, but unlike that in $\mathrm{B} 1 \mathrm{~s}$, within fassaite grains in $\mathrm{B} 2 \mathrm{~s}$ the $\mathrm{Ti}^{3+} /\left(\mathrm{Ti}^{3+}+\mathrm{Ti}^{4+}\right)$ ratio does not decrease from core to rim, and sharp enrichments ("spikes") in $\mathrm{Ti}^{3+}$ and $\mathrm{V}$ are not observed. Sector-zoned fassaite is much more common in B2s than in B1s. The differences we observed can be accounted for by the differences in bulk compositions between B1s and B2s. Type B2 inclusions tend to have higher $\mathrm{SiO}_{2}$ contents, hence higher An/Ge component ratios, than Type B1s. Phase equilibria show that, compared to B1s, in B2s less melilite should crystallize prior to the appearance of fassaite, so that in B2s a higher proportion of melilite cocrystallizes with fassaite, causing more of the crystals to be reversely zoned; more melilite crystallizes while adjacent to other crystals, leading to asymmetrical zoning; and with more liquid available, transport of components to growing fassaite occurs more readily than in B1s, facilitating crystal growth and giving rise to sector zoning. The lack of zoning with respect to $\mathrm{Ti}^{3+} / \mathrm{Ti}^{\text {tot }}$ and the absence of $\mathrm{Ti}^{3+}-$, V-rich spikes suggest that Type $\mathrm{B} 2$ melts maintained equilibrium with the nebular gas throughout crystallization, while the interiors of B1s were probably isolated from the gas, perhaps by their melilite mantles. This makes the similarity of Na-Åk relationships in B1 and B2 melilite difficult to understand, but apparently enclosure by melilite mantles was not necessary for the retention of $\mathrm{Na}_{2} \mathrm{O}$ during crystallization of Type $\mathrm{B}$ refractory inclusions.
\end{abstract}

(c) 2005 Elsevier Inc. All rights reserved.

\section{Introduction}

There are two major types of coarse-grained, Ca-, Alrich refractory inclusions (CAIs) found in carbonaceous chondrites: the Type As, which are extremely melilite-rich, with minor spinel and clinopyroxene [the Ti-, Al-rich variety termed "fassaite" by Dowty and Clark (1973)]; and the Type Bs, which also contain melilite but have a much higher fassaite/melilite ratio than the As and minor to moderate

\footnotetext{
* Corresponding author. Fax: +1 7737029505.

E-mail address: sbs8@midway.uchicago.edu (S.B. Simon).
}

spinel and anorthite contents. The Type Bs are subdivided into two textural subtypes: the B1s, which have a meliliterich outer mantle enclosing a pyroxene-rich core; and the B2s, which have a rather homogeneous distribution of phases (Wark and Lovering, 1977). The petrology of Type Bs is generally thought to be well understood, but actually most of this knowledge is based upon studies of Type B1 inclusions and on experiments with analogs of Type B1 bulk compositions. Type B2 inclusions tend to be more $\mathrm{SiO}_{2}$-rich than B1s (Stolper, 1982; Wark and Lovering, 1982; Simon and Grossman, 2004), however, so inferences about the formation of CAIs that are based on studies of 
Type B1 compositions should probably not be routinely extended to Type B2s. Despite the vast amount of work that has been done on Type B inclusions, features of B1s and B2s have not been systematically compared, except for one study (Wark and Lovering, 1982), which mainly considered their petrographic features, with a brief treatment of mineral chemistry. That work reported that melilite and fassaite have wider composition ranges in Type $\mathrm{B} 1$ inclusions, and thus tend to be more strongly zoned, than in B2s, but zoning within grains was not described. Wark and Lovering (1982) observed, and we note here, that there is a textural continuum among the Type Bs, from true B1s with thick, continuous melilite mantles, through those without mantles but with some enrichment in melilite at their rims, to true, homogeneous Type B2s. Mineralchemical criteria for distinguishing B2s from B1s would be useful in classification of inclusions in which the textures are ambiguous.

Some basic questions we are addressing in this study are: (1) What are the zoning patterns and ranges of composition of melilite and fassaite in Type B2 inclusions? (2) Are these patterns and ranges related in a systematic way to inclusion bulk composition? (3) Does melilite in Type $\mathrm{B} 2 \mathrm{~s}$, like that in $\mathrm{B} 1 \mathrm{~s}$, undergo late zoning reversals with respect to åkermanite content (MacPherson et al., 1984)? (4) How is melilite in Type B2 inclusions zoned with respect to $\mathrm{Na}$ ? (5) Are V-Ti "spikes" like those seen in fassaite in Type B1 inclusions (Simon and Grossman, 1991) also observed in fassaite in Type B2 inclusions? While Type B inclusions are classified on the basis of whether or not they exhibit continuous melilite mantles, there may be other petrologic differences between inclusions whose interiors were enclosed in melilite mantles throughout most of their crystallization history and inclusions that do not have melilite mantles. Assuming that early formed melilite mantles isolated the interiors of Type B1 inclusions from the nebular gas, whereas in the absence of mantles in partially molten Type B2s, the melt remained in communication with the nebular gas, Types B1 and B2 inclusions could be expected to have differing $\mathrm{Na}-\AA \mathrm{k} k$ systematics in melilite and $\mathrm{Ti}^{3+} /$ $\left(\mathrm{Ti}^{3+}+\mathrm{Ti}^{4+}\right)$ ratios in fassaite. Documentation of fundamental petrologic differences between Types B1 and B2 inclusions, and determination of which features can be attributed to bulk composition differences and which may depend upon the presence or absence of a melilite mantle, will improve our understanding of the formation of both suites. Preliminary results of this work were reported by Simon and Grossman (2003a,b).

\section{Analytical methods}

One or two polished thin sections of each inclusion were studied optically and with a JEOL JSM-5800LV scanning electron microscope (SEM) equipped with an Oxford/Link ISIS-300 energy-dispersive X-ray analysis system. The SEM was used to obtain backscattered electron images of grains selected for analysis, and grain boundaries were determined by examination in transmitted light. Quantitative wavelength-dispersive analyses were obtained with a Cameca SX-50 electron microprobe operated at $15 \mathrm{kV}$ and $25 \mathrm{nA}$ (for melilite) or $50 \mathrm{nA}$ (for fassaite), with counting times of 10-30 s for peak and for background measurements for each analysis. Pure oxide, synthetic glass, and natural mineral standards were used. Electron probe data were reduced via the modified ZAF correction procedure PAP (Pouchou and Pichoir, 1984).

\section{Results}

\subsection{Description of samples}

For this study we used polished thin sections of Allende Type B2s from the suite of inclusions whose bulk compositions were determined by Simon and Grossman (2004). The inclusions are TS4, TS65, TS67, Golfball, TS21, TS8, and TS20. TS4 is a roughly rectangular-shaped inclusion with approximate dimensions of $6 \times 4 \mathrm{~mm}$. Two edges are smooth and two have broad, rounded embayments filled with accretionary rim material. Most melilite grains are anhedral, $\sim 500 \mu \mathrm{m}$ across, and have inclusions of spinel, fassaite, and secondary alteration products. Some melilite is recrystallized in a mosaic of subgrains. Fassaite is either subhedral with few spinel inclusions or coarser and anhedral with abundant, fine spinel inclusions. Anorthite is anhedral and typically $\sim 200 \mu \mathrm{m}$ across. TS65 and TS67 are both large, rounded CAIs $\sim 7 \mathrm{~mm}$ across with equant anhedral to subhedral melilite, fassaite, and anorthite grains $\sim 200 \mu \mathrm{m}$ across throughout the inclusions. Finegrained spinel occurs enclosed in all phases and in dense knots between phases. Golfball is not a typical Type B2 inclusion. It is a unique Type B inclusion, described in detail elsewhere (Simon et al., 2005), with a melilite-rich core and fassaite-rich mantle. TS21 is a rounded inclusion with subhedral melilite and fassaite grains that are mostly $\sim 500 \mu \mathrm{m}$ across. Anorthite is anhedral and coarse, up to $700 \mu \mathrm{m}$ across. TS 8 and TS20 are oval and round inclusions, respectively, that are dominated by coarse, anhedral fassaite and anorthite, typically $500 \mu \mathrm{m}$ across, enclosing fine spinel. Melilite occurs as laths and is sparse compared to the other inclusions.

In Fig. 1, compositions of these inclusions, four Type B1s and CAIB, the Type B average used by Stolper (1982) and many others since, are projected from spinel onto the gehlenite $\left(\mathrm{Ca}_{2} \mathrm{Al}_{2} \mathrm{SiO}_{7}\right)$-forsterite $\left(\mathrm{Mg}_{2} \mathrm{SiO}_{4}\right)$-anorthite $\left(\mathrm{CaAl}_{2} \mathrm{Si}_{2} \mathrm{O}_{8}\right)$ plane of the $\mathrm{CaO}-\mathrm{MgO}-\mathrm{Al}_{2} \mathrm{O}_{3}-\mathrm{SiO}_{2}$ (CMAS) system. The inclusion compositions were obtained and corrected to the solar $\mathrm{CaO} / \mathrm{Al}_{2} \mathrm{O}_{3}$ ratio according to the methods of Simon and Grossman (2004). While CAIB is a good analog for the bulk compositions of Type B1 inclusions, the compositions of Type B2 inclusions are not easily represented by one composition. The range of Type B2 compositions extends from below the center of the melilite + spinel field almost to the melilite-anorthite join, though most Type B2 inclusions plot between CAIB 


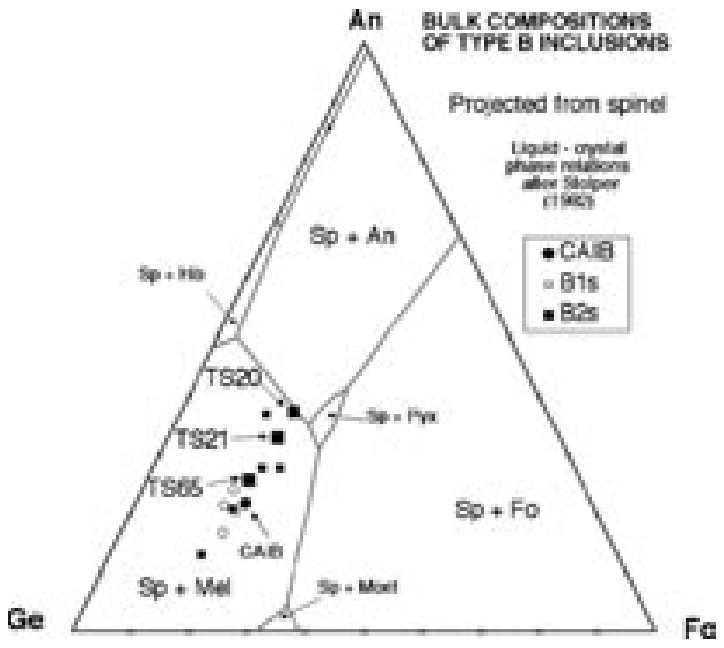

Fig. 1. Projection of bulk compositions of Type B inclusions from spinel $(\mathrm{Sp})$ onto the gehlenite $(\mathrm{Ge})$-anorthite $(\mathrm{An})$-forsterite $(\mathrm{Fo})$ plane in the CMAS system. Type B2s tend to have An/Ge component ratios higher than B1s. Compositions of inclusions discussed in detail have larger symbols. Inclusion compositions are from Simon and Grossman (2004). CAIB, average Type B composition of Stolper (1982); Hib, hibonite; Pyx, clinopyroxene; Mont, monticellite; Mel, melilite.

and the join. The samples emphasized in the present work are labeled. Among the other inclusions, one Type B2, TS4, has a bulk composition like a B1 and one, Efremovka sample E107, plots much closer to the gehlenite apex than any of the other Type B inclusions in the suite. This inclusion is anomalous petrographically as well. It may be a remelted B1 (Simon and Grossman, 2004), and as we are mainly interested in representative Type B2 inclusions, will not be considered further in this paper.

\subsection{Melilite}

\subsubsection{General features}

As shown in Fig. 1, much of the variation of the bulk compositions of Type B2s is manifested in their wider range of normative anorthite/gehlenite (An/Ge) component ratios than $\mathrm{B} 1 \mathrm{~s}$. With increasing $\mathrm{An} / \mathrm{Ge}$, reflecting increasing $\mathrm{SiO}_{2} / \mathrm{CaO}$ : less of the melilite field is traversed by the liquid composition during melilite crystallization before the onset of anorthite or fassaite crystallization; the melilite appearance temperature decreases; and the åkermanite content of the earliest melilite increases (Simon and Grossman, 2004). To see how this variation in bulk composition affects the compositions and zoning patterns of melilite, we studied in detail three Type B2 inclusions whose An/Ge ratios span most of the range of typical B2s: TS65 (An/Ge =0.46); TS21 (0.69); and TS20 (0.87). The An/Ge ratios of Type B1 inclusions are lower, typically between 0.3 and 0.4 (Simon and Grossman, 2004).

Backscattered electron images of representative areas of these inclusions are shown in Fig. 2, along with a view of the mantle of Allende Type B1 inclusion TS23 for compar- ison. Changes in modal mineralogy, especially near the outer margins of the inclusions, and texture can be seen with increasing An/Ge. The B1 inclusion has An/ $\mathrm{Ge}=0.34$ (Simon and Grossman, 2004) and is shown in Fig. 2A. It has a melilite mantle that is $\sim 0.5-1 \mathrm{~mm}$ thick, continuous, and nearly monomineralic, with sparse fassaite and spinel. The mantle encloses the relatively fassaite-rich, melilite-poor interior of the inclusion. An inclusion with a mantle thicker than that of TS23 would have a lower bulk An/Ge ratio. The outer $\sim 500 \mu \mathrm{m}$ of TS65 is enriched in melilite relative to the interior, but fassaite, spinel, and anorthite all occur near the edge of the inclusion (Fig. 2B), so melilite does not form a thick, continuous shell as in the B1s. Overall, in TS65 melilite is abundant (37.0 $\mathrm{wt} \%$ ) throughout the inclusion, fassaite $(28.4 \%)$ is less abundant than melilite and is anhedral, and anorthite is sparse $(16.0 \%)$. In TS21 (Fig. 2C), melilite is slightly less abundant $(33.3 \mathrm{wt} \%$ ) than in TS65, fassaite has about the same abundance $(27.5 \%)$, and there is much more anorthite $(22.6 \%)$. Fassaite and anorthite occur at the edge of the inclusion, which is not enriched in melilite. Fassaite had enough room to grow that it can be found with sharp crystal apices protruding into coarse anorthite (Fig. 2D). TS20 (Fig. 2E) has the least melilite $(24.8 \mathrm{wt} \%)$ and the most fassaite $(36.5 \%)$ of these inclusions, and about the same anorthite content as TS21 (22.1\%). These samples show that with increasing bulk An/Ge, melilite crystals tend to become smaller and less well-formed, increasingly contrasting with the large, well-formed laths of Type B1 inclusions, and their modal abundances at inclusion margins decrease.

Representative analyses of melilite from Types B1 and B2 inclusions are given in Table 1, and large data sets are compared in Figs. 3 and 4. Melilite in both B1s and B2s reaches maximum åkermanite $\left(\mathrm{Ca}_{2} \mathrm{MgSi}_{2} \mathrm{O}_{7}\right)$ contents of $\sim 75 \mathrm{~mol} \%$. The composition range of melilite in Type B2 inclusions that is observed here is much wider than that reported by Wark and Lovering (1982) and Wark et al. (2005). Fig. 3A is a histogram of melilite compositions in Type B1 inclusions, and it illustrates the contrasting core and mantle populations. Melilite in the outermost parts of the mantles has compositions that are more gehlenitic than melilite elsewhere in the B1s or in B2s. The mantles in general have higher proportions of melilite in the $\AA^{\circ} k_{10-}$ ${ }_{30}$ range than the $\mathrm{B} 1$ cores or most B2s. Figs. 3B-D are histograms of melilite compositions in the three Type B2 inclusions shown in Fig. 2, again in order of increasing bulk normative An/Ge ratio. Simon and Grossman (2004) showed that as this ratio increases, the average åk content of the melilite increases. Here, we see a shift in the histograms, from TS65 (Fig. 3B), with most analyses between $\AA^{\circ} k_{20}$ and $\AA \mathrm{k}_{30}$, and a peak at $\AA^{\circ} \mathrm{k}_{26-28}$, to TS21 (Fig. 3C) and TS20 (Fig. 3D), with peaks at $\AA_{40-44}$ and many analyses in the range from $\AA \mathrm{k}_{40}$ to $\AA \mathrm{k}_{50}$. In Fig. 3D, the small peak at $\AA^{\circ} k_{20-28}$ probably reflects the presence of relict grains.

Abundances of $\mathrm{Na}_{2} \mathrm{O}$ in melilite in the mantles and cores of Type B1 inclusions and in Type B2 inclusions are plotted 

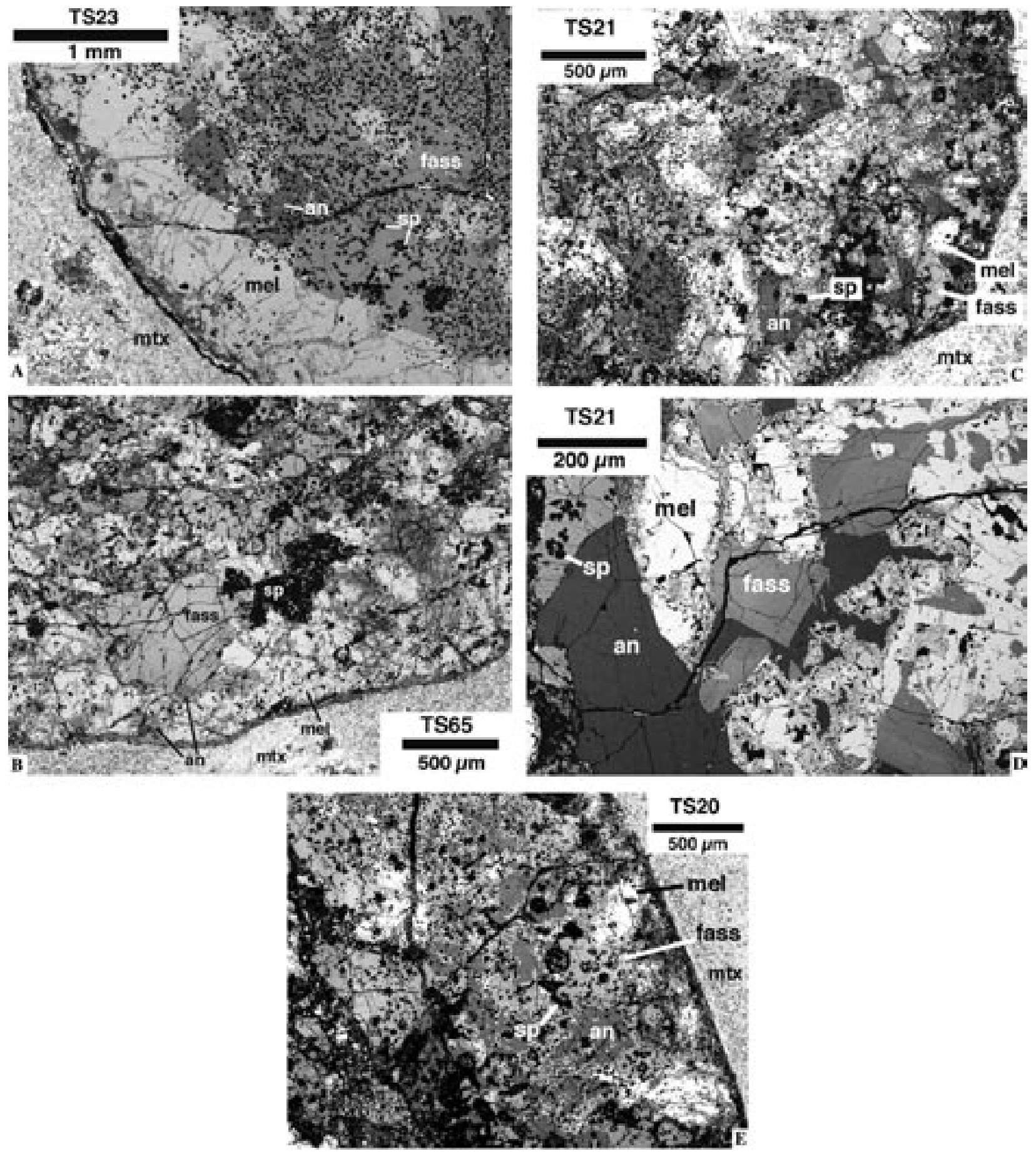

Fig. 2. Representative backscattered electron images of Types B1 and B2 inclusions from Allende, illustrating changes observed with increasing bulk An/ Ge component ratios. (A) TS23, a Type B1. Representative view of the melilite mantle (upper left to lower right), which encloses a relatively fassaite-rich core (upper right half of view). (B) TS65, with low An/Ge (0.46) among Type B2s. Note that rim region (lower portion of view) is fairly melilite-rich, though fassaite and anorthite also occur near the edge of the inclusion (left). Melilite occurs throughout the inclusion. (C) TS21, with higher An/Ge (0.69), has less melilite, more fassaite and anorthite than TS65, and no enrichment of melilite near the edge of the inclusion. (D) View of subhedral and euhedral fassaite in TS21. (E) TS20, with the highest An/Ge (0.87) of the suite. Note paucity of melilite and abundance of fassaite and anorthite. an, anorthite; fass, fassaite; mel, melilite; mtx, meteorite matrix; sp, spinel. 
Table 1

Electron microprobe analyses $(\mathrm{wt} \%)$ of melilite in Type B inclusions

\begin{tabular}{|c|c|c|c|c|c|c|c|c|c|c|c|c|}
\hline & 1 & 2 & 3 & 4 & 5 & 6 & 7 & 8 & 9 & 10 & 11 & 12 \\
\hline $\mathrm{Na}_{2} \mathrm{O}$ & 0.02 & BDL & 0.07 & 0.16 & 0.02 & 0.18 & 0.14 & 0.07 & 0.21 & 0.19 & 0.20 & BDL \\
\hline $\mathrm{MgO}$ & 0.71 & 2.66 & 6.48 & 8.32 & 4.85 & 7.22 & 9.28 & 3.76 & 5.49 & 9.10 & 7.35 & 3.09 \\
\hline $\mathrm{Al}_{2} \mathrm{O}_{3}$ & 35.55 & 29.82 & 19.90 & 15.03 & 24.17 & 18.02 & 12.86 & 27.03 & 22.61 & 12.76 & 17.89 & 28.48 \\
\hline $\mathrm{SiO}_{2}$ & 23.01 & 26.19 & 32.76 & 35.52 & 29.62 & 33.40 & 36.43 & 27.20 & 30.24 & 36.58 & 32.98 & 26.71 \\
\hline $\mathrm{CaO}$ & 40.88 & 41.14 & 41.31 & 41.17 & 41.29 & 40.97 & 40.90 & 41.00 & 40.55 & 40.60 & 41.12 & 40.89 \\
\hline $\mathrm{TiO}_{2}$ & 0.05 & 0.03 & BDL & BDL & BDL & 0.03 & BDL & 0.04 & 0.06 & BDL & BDL & BDL \\
\hline $\mathrm{FeO}$ & 0.11 & BDL & BDL & 0.03 & BDL & BDL & 0.04 & 0.06 & BDL & 0.12 & n.a. & n.a. \\
\hline \multicolumn{13}{|c|}{ Cations per seven oxygen anions } \\
\hline $\mathrm{Na}$ & 0.002 & 0 & 0.006 & 0.014 & 0.001 & 0.015 & 0.012 & 0.006 & 0.018 & 0.017 & 0.017 & 0 \\
\hline $\mathrm{Mg}$ & 0.048 & 0.181 & 0.437 & 0.562 & 0.330 & 0.491 & 0.631 & 0.258 & 0.376 & 0.620 & 0.502 & 0.212 \\
\hline $\mathrm{Al}$ & 1.906 & 1.606 & 1.061 & 0.804 & 1.299 & 0.968 & 0.691 & 1.468 & 1.224 & 0.688 & 0.966 & 1.544 \\
\hline $\mathrm{Si}$ & 1.046 & 1.197 & 1.482 & 1.611 & 1.351 & 1.523 & 1.662 & 1.254 & 1.389 & 1.673 & 1.511 & 1.228 \\
\hline $\mathrm{Ca}$ & 1.992 & 2.014 & 2.002 & 2.001 & 2.018 & 2.001 & 1.999 & 2.025 & 1.996 & 1.989 & 2.018 & 2.015 \\
\hline $\mathrm{Ti}$ & 0.002 & 0.001 & 0 & 0 & 0 & 0.001 & 0 & 0.001 & 0.002 & 0 & 0 & 0 \\
\hline Total cations & 5.000 & 4.999 & 4.988 & 4.993 & 4.999 & 4.999 & 4.997 & 5.014 & 5.005 & 4.992 & 5.014 & 4.999 \\
\hline Åk $\left(\mathrm{mol}^{\circ} \%\right)$ & 4.7 & 19.2 & 46.3 & 59.0 & 34.4 & 51.0 & 64.9 & 25.9 & 38.5 & 65.0 & 51.0 & 22.3 \\
\hline
\end{tabular}

1-4: Type B1, mantle. 5-7: Type B1, core. 8-12: Type B2. BDL: Below the detection limit of $0.017 \mathrm{wt}^{\mathrm{o}} \% \mathrm{Na}_{2} \mathrm{O}, 0.025 \mathrm{wt} \% \mathrm{TiO}_{2}$, or $0.027 \mathrm{wt} \% \mathrm{FeO}_{\text {. n.a.: }}$ not analyzed.

as a function of åkermanite content in Fig. 4. In both B1s and $\mathrm{B} 2 \mathrm{~s}, \mathrm{Na}_{2} \mathrm{O}$ contents are positively correlated with åkermanite contents and are typically $<0.1 \mathrm{wt} \%$ for $\AA \mathrm{k}_{<30}$, range from below detection to $\sim 0.2 \mathrm{wt} \%$ for $\AA \mathrm{k}_{30-50}$, and for $\AA \mathrm{A}_{>50}, \quad \mathrm{Na}_{2} \mathrm{O}$ contents are typically $>0.1 \mathrm{wt} \%$. The $\mathrm{B} 2 \mathrm{~s}$ contain more melilite with $\mathrm{Na}_{2} \mathrm{O}$ contents significantly elevated above the main trend. Type B2 inclusions are commonly more heavily altered than Type B1s (MacPherson et al., 1981; Beckett, 1986), and many of the analyses that are off the trend have probably been affected by secondary alteration. Apart from these analyses, the main trends of the data for both inclusion types are similar. Melilite in Type B2 inclusions clearly is not systematically depleted in $\mathrm{Na}_{2} \mathrm{O}$ relative to melilite in Type B1 inclusions.

\subsubsection{Zoning}

To see if melilite zoning patterns are related in a systematic way to bulk composition and for comparison with zoning seen in melilite in Type B1 inclusions, we conducted electron probe traverses across 6-21 melilite crystals in each of six inclusions, including the three B2s shown in Fig. 2. The traverses average 75 analysis points each with a spacing of $4 \mu \mathrm{m}$ between points. In Type B1s, melilite is typically normally zoned, having increasing $\mathrm{MgO}$, or åkermanite component contents, and decreasing $\mathrm{Al}_{2} \mathrm{O}_{3}$, or gehlenite component contents, from core to rim. Some grains exhibit zoning reversals, probably reflecting an increase in the $\mathrm{Al} / \mathrm{Mg}$ ratio of the residual liquid due to the onset of fassaite crystallization (MacPherson et al., 1984). In contrast, within each Type B2 inclusion we studied, we found a variety of zoning patterns in the melilite. None of the inclusions has a characteristic melilite zoning pattern associated with it.
Despite its B1-like bulk composition (Simon and Grossman, 2004), of the melilite grains we analyzed in TS4 only one is normally zoned (from $\AA^{\mathrm{k}} \mathrm{k}_{\sim 30}$ to $\AA^{\mathrm{k}} \mathrm{k}_{\sim 70}$ ). One grain is weakly reversely zoned from $\AA^{k_{57}}$ in its core to $\AA \mathrm{k}_{51}$ at its rim, and the rest are unzoned. A sampling of the electron probe traverses of melilite grains in TS65 is shown in Fig. 5. In this inclusion melilite crystals vary from unzoned (Fig. 5A) to strongly zoned (Fig. 5B). Some grains are only strongly zoned at one (Fig. 5C) or both (Fig. 5D) of their rims. Grains 2 and 3 are asymmetrically zoned, a feature commonly found in melilite in the Type B2 inclusions we studied. Without a reference point, such as the inclusion rim, to infer where crystallization began, we cannot say with certainty whether these grains are normally or reversely zoned. Some grains have reversely zoned cores and normally zoned rims (Fig. 5D). At the edge of the inclusion, melilite as gehlenitic as $\AA \mathrm{k}_{10}$ can be found, but otherwise most of the melilite in this inclusion is $\AA^{\mathrm{A}} \mathrm{k}_{>20}$ (Fig. 3). TS67, a Type B2 inclusion with a bulk composition very similar to that of TS65 (Simon and Grossman, 2004), also has grains with zoning patterns like those shown in Figs. $5 \mathrm{~A}, \mathrm{C}$, and D.

Examples of zoning patterns found in melilite in TS21 are shown in Fig. 6. Again there is a variety of zoning styles. Grains with small, normally zoned cores and thick, reversely zoned rims (e.g., Fig. 6A) are more common than in TS65. Note that almost the entire grain is reversely zoned, as compared to the outermost $\sim 25 \%$ or less of reversely zoned grains in Type B1 inclusions (MacPherson et al., 1984). Grains 2 and 3 (Figs. 6B and C) appear to be normally but asymmetrically zoned. Grains with one strongly zoned edge (e.g., Fig. 6C) are common. Other grains have no overall trend (Fig. 6D). Except for a grain near the rim of the inclusion, all melilite in TS21 that we 

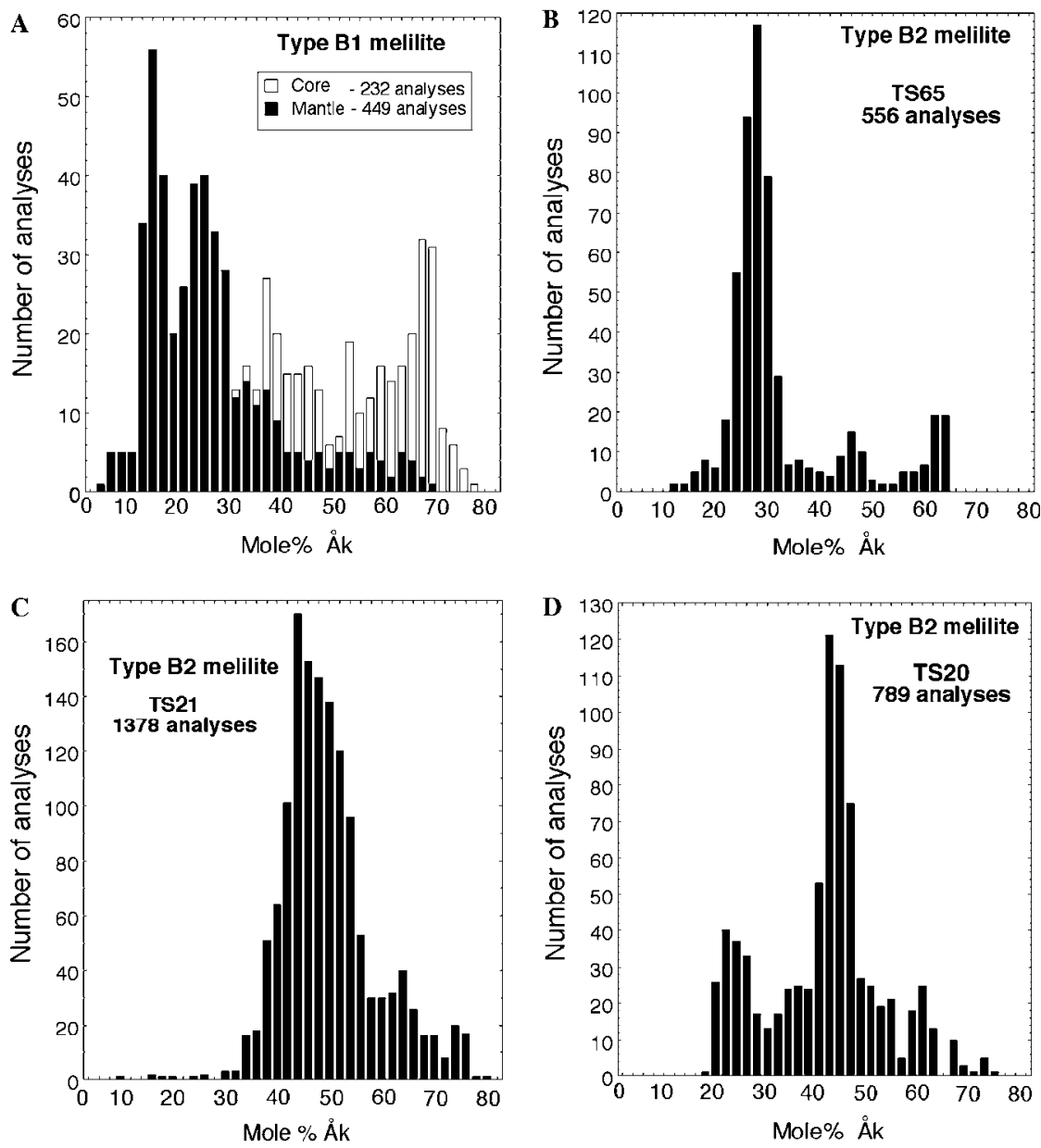

Fig. 3. Histograms of melilite compositions, in terms of mole \% åkermanite component. (A) Melilite in the cores and mantles of Type B1 inclusions. Core melilite is much more Åk-rich than mantle melilite. (B) Melilite in TS65, a Type B2 inclusion with a relatively low bulk normative An/Ge ratio of 0.46 . The histogram peak is slightly more Ak-rich than the peak of the B1 mantle melilites. (C) Melilite in TS21, a Type B2 inclusion with a higher An/Ge ratio, 0.69. The peak is at more Åk-rich compositions, $\AA^{k_{40-42}}$. (D) Melilite in TS20, a Type B2 inclusion with a normative An/Ge ratio of 0.87 , also dominated by $\AA \mathrm{k}_{40-50}$.

analyzed is $\AA \mathrm{k}_{30-75}$. Melilite in TS8, with the next-highest $\mathrm{An} / \mathrm{Ge}$ ratio, is mostly unzoned at $\AA^{\circ} \mathrm{k}_{\sim 40}$ or normally zoned.

In TS20, which has the highest $\mathrm{An} / \mathrm{Ge}$ ratio of all the inclusions in the suite, melilite commonly occurs as small, isolated grains that are normally and/or asymmetrically zoned. Other grains are very weakly zoned or unzoned, except for a strongly zoned rim. We did not find any grains with thick, reversely zoned rims like those in TS21. In addition to the melilite crystals in TS20 that were analyzed for documentation of zoning patterns and the composition histogram, we analyzed 12 grains that occur at or near the edge of the inclusion. We found that all are normally zoned, with åkermanite contents increasing with increasing distance from the edge of the inclusion. In addition, in half of the rim crystals analyzed, the outermost $20-50 \mu \mathrm{m}$ (i.e., closest to the edge of the inclusion) are $\AA$ k-depleted by $\sim 10-20 \mathrm{~mol} \%$ relative to both the zoning trends of the crystals and to the initial melilite $\left(\AA_{\mathrm{k}} \mathrm{k}_{\sim 40}\right)$ expected for an inclusion with the composition of TS20, as predicted from the melilite composition contours of Beckett et al. (1999). Similar depletions in $\AA \mathrm{k}$ relative to the predicted initial compositions were observed in other B2s we studied, and they have also been reported for the outermost melilite in Type B1 (e.g., MacPherson et al., 1989; Davis et al., 1992) and compact Type A (Simon et al., 1999) inclusions, suggesting that all three inclusion types have experienced similar episodes of evaporative loss from their outermost margins.

\subsection{Fassaite}

\subsubsection{General features}

This unusual variety of clinopyroxene, is a major phase in Type B inclusions. It can be described as a solid solution of four endmember components: Diopside (Di, $\mathrm{CaMgSi}_{2} \mathrm{O}_{6}$ ); 

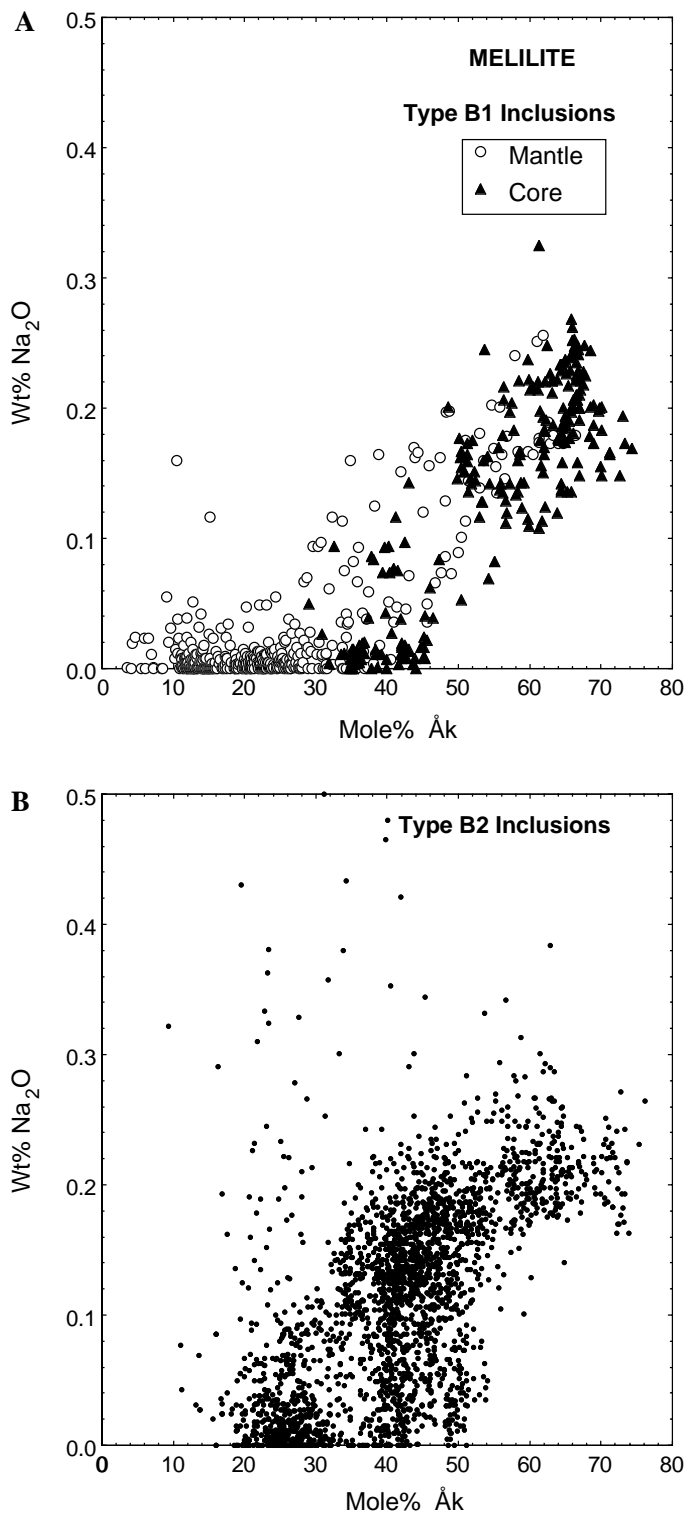

Fig. 4. Plots of $\mathrm{Na}_{2} \mathrm{O}$ contents against mole $\% \AA \mathrm{k}$ in melilite from (A) Type B1 and (B) Type B2 inclusions. In both types of inclusions, $\mathrm{Na}_{2} \mathrm{O}$ contents are positively correlated with Åk.

Ca-Tschermak's molecule (CaTs, CaAlAlSiO ${ }_{6}$; a $\mathrm{Ti}^{3+}$

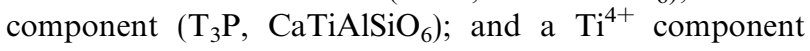
$\left(\mathrm{T}_{4} \mathrm{P}, \mathrm{CaTiAl}_{2} \mathrm{O}_{6}\right)$. This phase was first reported in Allende inclusions by Marvin et al. (1970), and its crystal structure refined by Dowty and Clark (1973). Many analyses have been published in the years since then in detailed studies (e.g., Simon et al., 1991) and in review papers (e.g., Brearley and Jones, 1998). Representative analyses of fassaite from Type B2 inclusions we studied are given in Table 2. Note that three of the four main components of fassaite are Al-bearing. Fassaite $\mathrm{Al}_{2} \mathrm{O}_{3}$ contents, plotted against $\mathrm{MgO}$ in Fig. 7, range from 14 to $22 \mathrm{wt} \%$ in $\mathrm{B} 1 \mathrm{~s}$ and from
12 to $22 \mathrm{wt} \%$ in B2s. In Type B1s (Fig. 7A), most fassaite in the inclusion cores is $\mathrm{MgO}$-rich and $\mathrm{Al}_{2} \mathrm{O}_{3}$-poor compared to that in the mantles, and the $\mathrm{Al}_{2} \mathrm{O}_{3}$ contents are weakly anticorrelated with $\mathrm{MgO}$ contents. There is also very little overlap among the mantle fassaites from the three different Type B1 inclusions represented in Fig. 7. The mantle of TS34 contains anomalous, Ti-rich, Mg-poor fassaite grains, which were first reported by Simon et al. (1991). Fassaite in the mantle of 5241 is generally $\mathrm{Al}_{2} \mathrm{O}_{3}$ poor compared to that in the mantles of TS23 and TS34.

Contents of $\mathrm{Al}_{2} \mathrm{O}_{3}$ and $\mathrm{MgO}$ in fassaite from three Type $\mathrm{B} 2$ inclusions are plotted in Fig. 7B. In $\mathrm{B} 2 \mathrm{~s}, \mathrm{Al}_{2} \mathrm{O}_{3}$ contents are more strongly anticorrelated with $\mathrm{MgO}$ contents than they are in B1s. Each of the B2s plotted has two populations of pyroxene compositions; one is Al-poor and $\mathrm{Mg}$ rich, and the other is Al-rich and Mg-poor. This reflects the effect of sector zoning with respect to the CaTs (Al) and Di (Mg) components. This style of zoning is discussed below.

The Ti contents of fassaite are commonly reported as $\mathrm{TiO}_{2}$ or $\mathrm{TiO}_{2}{ }^{\text {tot }}$, but in both $\mathrm{B} 1 \mathrm{~s}$ and $\mathrm{B} 2 \mathrm{~s}$, a significant portion of the Ti is trivalent. Separate $\mathrm{TiO}_{2}$ and $\mathrm{Ti}_{2} \mathrm{O}_{3}$ contents can be calculated accurately from stoichiometry, assuming four cations, including one $\mathrm{Ca}$, per six oxygen anions (Beckett, 1986) for fassaite with $\geqslant 4 \mathrm{wt}^{\%} \mathrm{TiO}_{2}{ }^{\text {tot }}$. Much of the published data, however, come from either Type B1 inclusions or unspecified Type Bs, without a systematic comparison of fassaite from Type B1s with that from Type B2s.

Relationships between the $\mathrm{Ti}^{3+} / \mathrm{Ti}^{\text {tot }}\left[\mathrm{Ti}^{3+} /\right.$ $\left.\left(\mathrm{Ti}^{3+}+\mathrm{Ti}^{4+}\right)\right]$ ratio and total $\mathrm{Ti}_{2} \mathrm{O}_{3}+\mathrm{TiO}_{2}$ in Type $\mathrm{B}$ fassaite are illustrated in Fig. 8. As Fig. 8A shows, the range of Ti oxide contents of mantle fassaite in the B1s extends to values higher than those of fassaite in the cores of the inclusions. In contrast, we found that rim and interior pyroxenes in Type B2 inclusions have virtually the same maximum $\mathrm{Ti}$ oxide contents. Values of $\mathrm{Ti}^{3+} / \mathrm{Ti}^{\text {tot }}$ between 0.3 and 0.7 are common in both inclusion types. The mantle fassaite in TS34 has $\mathrm{Ti}^{3+} / \mathrm{Ti}^{\mathrm{tot}}$ between 0.7 and 0.8 . The average $\mathrm{Ti}^{3+} / \mathrm{Ti}^{\text {tot }}$ ratio in $\mathrm{B} 1$ fassaite is higher than that in the $\mathrm{B} 2 \mathrm{~s}$, but the averages are within 1 s.d. of each other $(0.583 \pm 0.137$ for the B1s, $0.501 \pm 0.125$ for the B2s). With some scatter, $\mathrm{Ti}^{3+} / \mathrm{Ti}^{\text {tot }}$ is correlated with total $\mathrm{Ti}_{2} \mathrm{O}_{3}+\mathrm{TiO}_{2}$, more strongly in Type B1 fassaite (Fig. 8A) than in Type B2 fassaite (Fig. 8B). This is related to differences in zoning styles within single crystals, which are discussed below.

The contents of $\mathrm{Sc}_{2} \mathrm{O}_{3}$ in fassaite in two Type $\mathrm{B} 1$ and three Type $\mathrm{B} 2$ inclusions are plotted against total Ti oxide contents in Fig. 9. In both $\mathrm{B} 1$ and $\mathrm{B} 2$ fassaite, $\mathrm{Sc}_{2} \mathrm{O}_{3}$ contents, as well as those of $\mathrm{V}_{2} \mathrm{O}_{3}$, are positively correlated with total Ti oxides. Mantle fassaite can be quite Ti-, Sc-, and V-rich. Fassaite in the cores of Type B1 inclusions also has higher maximum contents of these oxides than does fassaite in Type B2 inclusions, reaching $\sim 12.3 \mathrm{wt} \%$ $\mathrm{Ti}_{2} \mathrm{O}_{3}+\mathrm{TiO}_{2}$ vs. $\sim 10.4 \mathrm{wt}^{\%} \%$ in the $\mathrm{B} 2 \mathrm{~s}, 0.30 \mathrm{wt} \% \mathrm{Sc}_{2} \mathrm{O}_{3}$ vs. 0.21 , and $0.76 \mathrm{wt}^{\%} \% \mathrm{~V}_{2} \mathrm{O}_{3}$ vs. 0.64 . The 1448 analyses of (core) Type B1 fassaite that are plotted in Fig. 9 average 

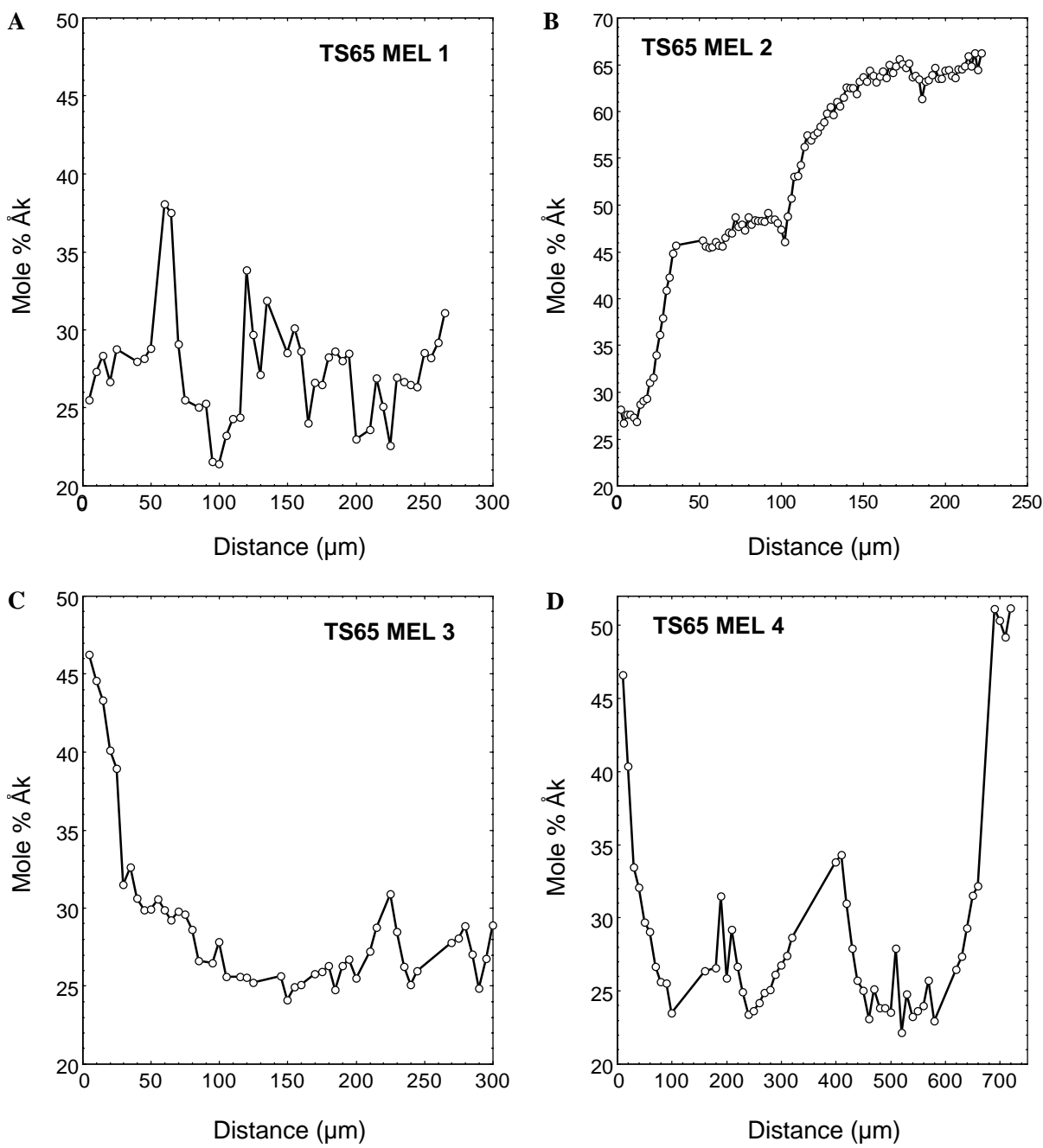

Fig. 5. Results of rim-to-rim electron probe traverses across melilite crystals in TS65 (An/Ge =0.46). (A) Unzoned grain. (B) Strongly zoned grain. (C) Grain with a strongly zoned rim. (D) Grain with a small, reversely zoned core and a strongly zoned rim. Most compositions in this inclusion are more magnesian than $\AA \mathrm{k}_{20}$.

$7.3 \mathrm{wt}^{\%} \% \mathrm{Ti}_{2} \mathrm{O}_{3}+\mathrm{TiO}_{2}$ and the 1231 Type $\mathrm{B} 2$ analyses average $5.7 \mathrm{wt} \%$. Wark and Lovering (1982) also found that fassaite in Type B2 inclusions tends to have Ti contents lower than that in Type B1 inclusions. Note that in Fig. 9, with increasing bulk normative An/Ge in the B2s (from TS65 to TS21 through TS20, respectively), the degree of overlap with the Type B1 fassaite decreases, due to generally decreasing $\mathrm{Ti}$ oxide contents in the Type B2 fassaite. This is consistent with the observation that among Type B inclusions, although fassaite abundances increase as An/Ge increases, bulk Ti contents do not (Simon and Grossman, 2004).

\subsubsection{Core-rim zoning in single crystals}

Zoning trends within fassaite grains from several Allende Type B1 inclusions and one Type B2 were documented by Simon et al. (1991). They showed that Ti and Sc contents decrease while those of $\mathrm{Mg}$ and $\mathrm{Si}$ increase from core to rim in zoned grains. Grains analyzed for the present study show similar trends. The lower maximum contents of Sc and Ti oxides (Fig. 9) result in relatively muted zoning trends in fassaite in Type B2 inclusions compared to that in Type B1s. The trends in a representative grain are shown in Fig. 10. As seen in many fassaite grains in Type $\mathrm{B} 1$ inclusions, total $\mathrm{Ti}_{2} \mathrm{O}_{3}+\mathrm{TiO}_{2}, \mathrm{~V}_{2} \mathrm{O}_{3}$, and $\mathrm{Sc}_{2} \mathrm{O}_{3}$ contents decrease from core to rim in Type $\mathrm{B} 2 \mathrm{~s}, \mathrm{~V}_{2} \mathrm{O}_{3}$ more sharply than $\mathrm{Sc}_{2} \mathrm{O}_{3}$, while $\mathrm{MgO}$ and $\mathrm{SiO}_{2}$ increase. Note, however, that the overall trend of the $\mathrm{Ti}^{3+} / \mathrm{Ti}^{\text {tot }}$ with distance is flat, as $\mathrm{Ti}_{2} \mathrm{O}_{3}$ and $\mathrm{TiO}_{2}$ both decrease from core to rim. In contrast, in many grains in Type $\mathrm{B} 1$ inclusions, $\mathrm{Ti}_{2} \mathrm{O}_{3}$ decreases steeply while $\mathrm{TiO}_{2}$ decreases slightly or remains the same, leading to decreases in $\mathrm{Ti}^{3+} / \mathrm{Ti}^{\text {tot }}$ from core to rim (Simon et al., 1991). The behavior in B1s is consistent with calculated fassaite/liquid distribution coefficients of $\sim 2.7$ for $\mathrm{Ti}^{3+}$ and $\sim 0.7$ for $\mathrm{Ti}^{4+}$, which are based on the composition of the core of a fassaite in a Type B1 inclusion 

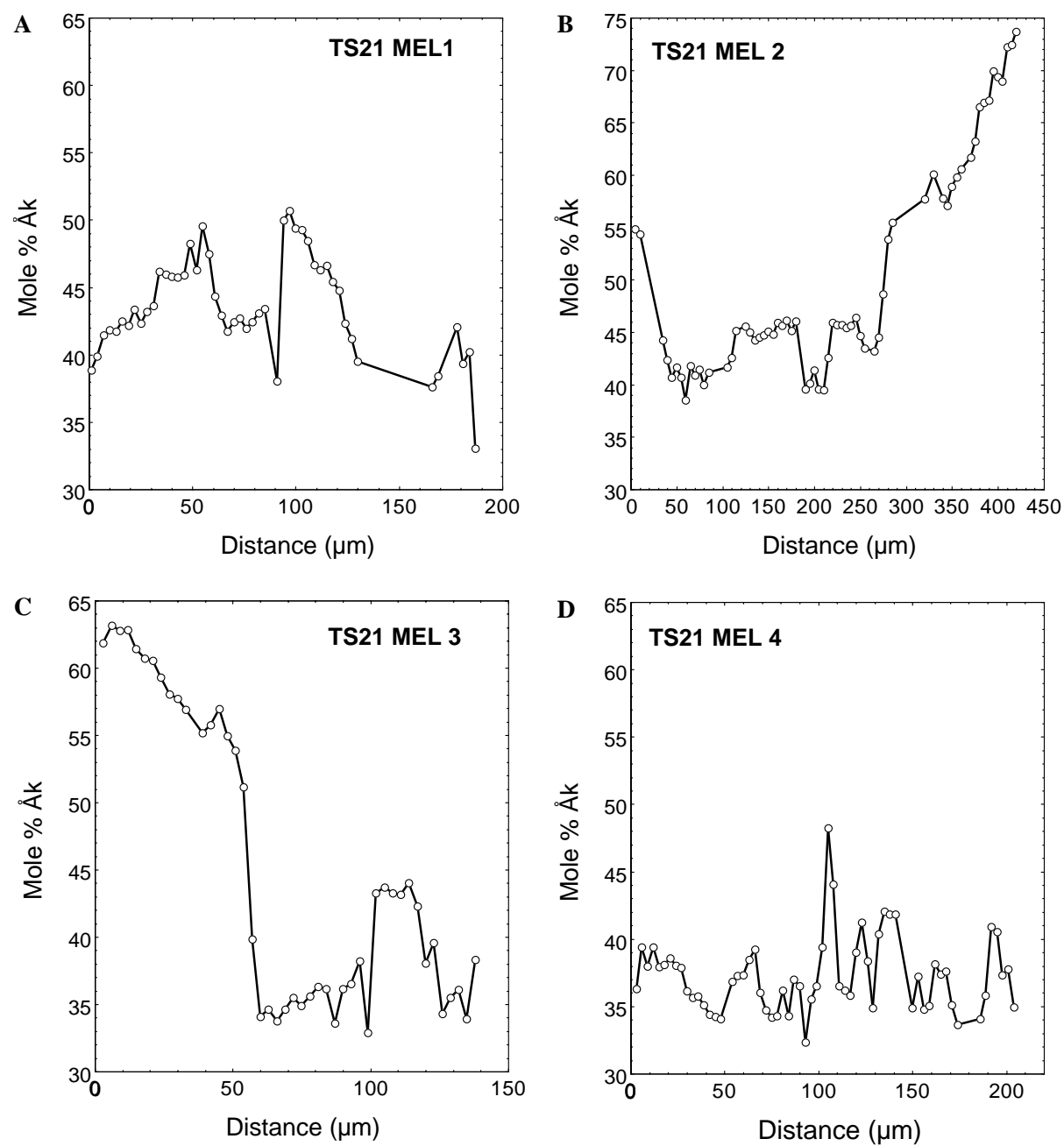

Fig. 6. Results of rim-to-rim electron probe traverses across melilite crystals in TS21 (An/Ge =0.69). (A) A mostly reversely zoned grain with a small, normally zoned core. (B and C) Asymmetrically zoned grains. (D) An unzoned grain. Most compositions in this inclusion are more magnesian than Åk 35 .

(Simon et al., 1991). During fractional crystallization with these distribution coefficients, the $\mathrm{Ti}^{3+} / \mathrm{Ti}^{\text {tot }}$ ratio of the residual liquid will decrease.

A common feature of fassaite in Type $\mathrm{B} 1$ inclusions is sharp increases, or "spikes," in their $\mathrm{Ti}_{2} \mathrm{O}_{3}$ and $\mathrm{V}_{2} \mathrm{O}_{3}$ contents, near crystal rims (Simon and Grossman, 1991). These can be seen in backscattered electron images (e.g., Fig. 11A) as thin, light bands which fade toward the crystal rims. The contacts (arrows) between the pre-spike, Ti-poor fassaite (dark) and the Ti-rich fassaite (light) at the spikes are sharp and irregular, scalloped or embayed (Simon et al., 1992). The results of an electron probe traverse across a spike are shown in Figs. 11B and C. The analyses show that at the spike, in addition to $\mathrm{Ti}_{2} \mathrm{O}_{3}$ and $\mathrm{V}_{2} \mathrm{O}_{3}$, total $\mathrm{Ti}$ oxides and $\mathrm{Ti}^{3+} / \mathrm{Ti}^{\text {tot }}$ also increase, but $\mathrm{Sc}_{2} \mathrm{O}_{3}$ does not. In addition, in some spikes, including the one illustrated here, $\mathrm{TiO}_{2}$ contents decrease when $\mathrm{Ti}_{2} \mathrm{O}_{3}$ increases. While grains with these spikes are easily found in Type $\mathrm{B} 1$ inclusions, they are not found in Type B2 inclusions, constitut- ing another difference between fassaite in B1 and B2 inclusions. We are continuing to investigate the spikes (Sutton et al., 2002) and their origin is not yet completely understood, but the preliminary data suggest that a redox reaction is involved, as suggested by Simon et al. (1992). Although $\mathrm{Ti}, \mathrm{V}$, and $\mathrm{Sc}$ are all compatible in fassaite (Simon et al., 1991), only the elements with variable oxidation states, Ti and V, increase at the spikes.

\subsubsection{Sector zoning}

In addition to concentric, core-rim zoning, fassaite in Type B2 inclusions commonly exhibits sector zoning. This style of zoning, in which the shapes of the sectors are crystallographically controlled, is not commonly found in Type B1 inclusions. A sector-zoned crystal can be described as consisting of pyramids whose apices meet at the core and whose bases form the crystal faces (Hollister and Gancarz, 1971). A crystal divided into two pairs of sectors is illustrated in Fig. 12A. In such a crystal, the 
Table 2

Electron microprobe analyses (wt $\%$ ) of sector-zoned fassaite from Allende Type B2 inclusions

\begin{tabular}{|c|c|c|c|c|c|c|c|}
\hline & 1 & 2 & 3 & 4 & 5 & 6 & 7 \\
\hline $\mathrm{MgO}$ & 11.55 & 10.70 & 8.57 & 11.11 & 9.30 & 10.80 & 8.56 \\
\hline $\mathrm{Al}_{2} \mathrm{O}_{3}$ & 15.44 & 16.57 & 20.51 & 16.07 & 19.80 & 16.02 & 20.55 \\
\hline $\mathrm{SiO}_{2}$ & 42.72 & 40.66 & 36.81 & 42.32 & 38.89 & 41.43 & 37.34 \\
\hline $\mathrm{CaO}$ & 25.43 & 25.14 & 25.05 & 25.24 & 25.21 & 24.74 & 24.46 \\
\hline $\mathrm{Sc}_{2} \mathrm{O}_{3}$ & 0.03 & 0.12 & 0.17 & 0.11 & 0.11 & 0.03 & 0.10 \\
\hline $\mathrm{TiO}_{2}{ }^{\text {tot }}$ & 4.81 & 6.62 & 8.28 & 5.20 & 6.51 & 5.26 & 8.73 \\
\hline $\mathrm{V}_{2} \mathrm{O}_{3}$ & 0.13 & 0.35 & 0.52 & 0.25 & 0.26 & 0.11 & 0.31 \\
\hline $\mathrm{Ti}_{2} \mathrm{O}_{3}$ & 2.19 & 3.01 & 4.10 & 2.72 & 3.32 & 2.82 & 4.81 \\
\hline $\mathrm{TiO}_{2}$ & 2.38 & 3.25 & 3.73 & 2.15 & 2.82 & 2.09 & 3.26 \\
\hline Sum & 99.87 & 99.80 & 99.46 & 100.01 & 99.76 & 98.13 & 99.39 \\
\hline \multicolumn{8}{|c|}{ Cations per six oxygen anions } \\
\hline $\mathrm{Si}$ & 1.565 & 1.497 & 1.372 & 1.548 & 1.435 & 1.544 & 1.379 \\
\hline $\mathrm{Al}$ & 0.435 & 0.503 & 0.628 & 0.452 & 0.565 & 0.456 & 0.621 \\
\hline $\mathrm{Al}$ & 0.232 & 0.216 & 0.272 & 0.240 & 0.296 & 0.247 & 0.274 \\
\hline $\mathrm{Mg}$ & 0.631 & 0.587 & 0.476 & 0.606 & 0.511 & 0.600 & 0.471 \\
\hline $\mathrm{Fe}$ & 0.000 & 0.000 & 0.000 & 0.001 & 0.001 & 0.002 & 0.000 \\
\hline $\mathrm{Sc}$ & 0.001 & 0.004 & 0.006 & 0.003 & 0.003 & 0.001 & 0.003 \\
\hline V & 0.004 & 0.010 & 0.015 & 0.007 & 0.007 & 0.003 & 0.009 \\
\hline $\mathrm{Ti}^{3+}$ & 0.067 & 0.093 & 0.127 & 0.084 & 0.103 & 0.089 & 0.150 \\
\hline $\mathrm{Ti}^{4+}$ & 0.066 & 0.090 & 0.105 & 0.059 & 0.078 & 0.059 & 0.092 \\
\hline $\mathrm{Ti}^{3+} / \mathrm{Ti}^{\mathrm{tot}}$ & 0.505 & 0.507 & 0.549 & 0.584 & 0.567 & 0.599 & 0.621 \\
\hline $\mathrm{xDi}$ & 63.38 & 59.53 & 48.57 & 61.27 & 51.78 & 60.36 & 47.71 \\
\hline $\mathrm{xCaTs}$ & 23.31 & 21.89 & 27.75 & 24.26 & 29.93 & 24.80 & 27.74 \\
\hline xTi3 & 6.73 & 9.43 & 13.00 & 8.45 & 10.36 & 8.89 & 15.24 \\
\hline xTi4 & 6.59 & 9.16 & 10.67 & 6.02 & 7.93 & 5.94 & 9.31 \\
\hline
\end{tabular}

1 and 2: TS21, Di-rich. 3: TS21, Di-poor. 4: TS20, Di-rich. 5: TS20, Di-poor. 6: TS65, Di-rich. 7: TS65, Di-poor. BDL: below detection limit of electron probe of $0.027 \mathrm{wt} \% \mathrm{FeO}$.

lined sector and the corresponding one (to the left) would have virtually identical compositions, and the upper and lower (unlined) sectors would be quite similar to each other. A plane through the center of such a crystal would reveal the four sectors in an " $\mathrm{X}$ " pattern. As noted by Beckett (1986), in CAIs sector-zoned fassaite crystals have regions that are either $\mathrm{Mg}$-, Si-rich or Al-rich, so the zoning is mainly defined by variations of the Di and CaTs components. The CaTs-rich sectors are slightly more Tirich than the Di-rich sectors, allowing the zoning to be seen with backscattered electron imaging. An excellent example, from TS21, is shown in the upper left image in Fig. 12B. The section through the crystal is just slightly off-center, as the apices of the (dark) Di-rich sectors almost meet. Note the sharp contacts between the Di-rich and CaTs-rich sectors. The zoning is not concentric, but has normal, core-rim zoning superimposed. Electron albedo decreases toward the rim of the grain, especially in the CaTs-rich sectors, reflecting the decrease in $\mathrm{Ti}$ contents from core to rim. In the three X-ray maps in Fig. 12B, the CaTs-rich sectors are relatively light in the Al map and dark in the $\mathrm{Mg}$ and $\mathrm{Si}$ maps. The reverse is true for the Di-rich sectors.

Fig. 12B also shows the location of an electron probe traverse across the grain in the image, and the results are illustrated in Fig. 12C. The data are plotted in terms of the four fassaite endmembers, and representative analyses of Di-rich and Di-poor sectors from this and two other crystals are given in Table 2. Typically, Di-rich sectors are $\sim 10 \mathrm{~mol} \%$ richer in $\mathrm{Di}, \sim 6 \mathrm{~mol}^{\%} \%$ poorer in CaTs, and $\sim 4 \mathrm{~mol} \%$ poorer in $\mathrm{T}_{3} \mathrm{P}+\mathrm{T}_{4} \mathrm{P}$ components than adjacent CaTs-rich sectors. In the traverse that is shown, within the Di-rich sectors the Di component increases toward the edge of the grain and the total $\mathrm{Ti}$ components decrease. Thus, this grain has normal core-to-rim zoning superimposed on the sector zoning. The contents of $\mathrm{V}_{2} \mathrm{O}_{3}$ and $\mathrm{Sc}_{2} \mathrm{O}_{3}$ do not change dramatically at the sector boundaries; they decrease smoothly from core to rim, also reflecting normal zoning.

\section{Discussion}

\subsection{Inferences from melilite}

Melilite in Type B2 inclusions exhibits both similarities and differences in occurrence, compositions, and zoning patterns compared to those in Type B1 inclusions. Some of these features can be understood when considered along with the bulk compositions of the inclusions and their associated phase equilibria. As shown in Fig. 1, the ranges of the bulk compositions of Type B1 and typical B2 inclusions overlap only slightly. Type B2 inclusions tend to have 

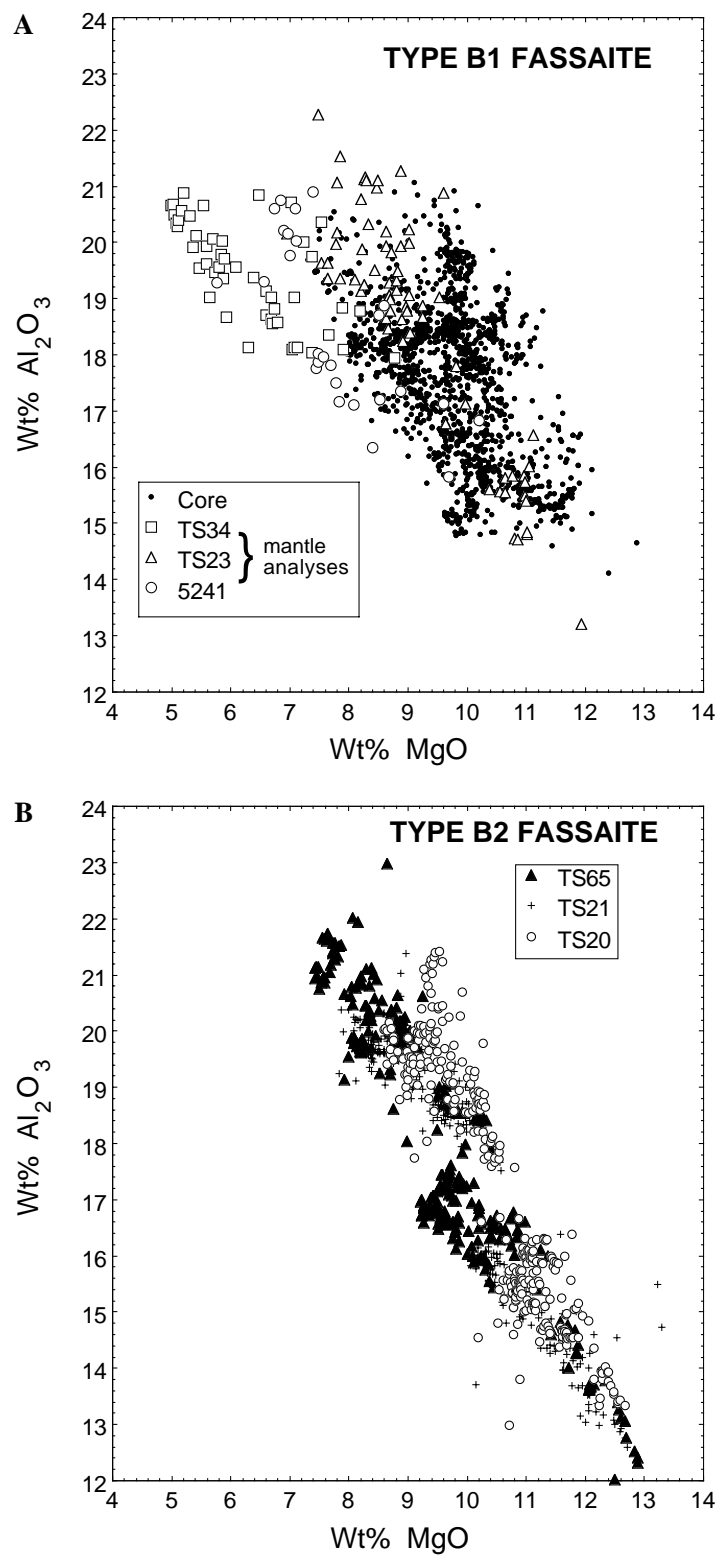

Fig. 7. Plots of $\mathrm{wt}^{2} \% \mathrm{Al}_{2} \mathrm{O}_{3}$ vs. wt $\% \mathrm{MgO}$ in fassaite in (A) Type $\mathrm{B} 1$ inclusions and (B) Type $\mathrm{B} 2$ inclusions. Compositions of fassaite in the mantles of three different B1 inclusions have little overlap with each other. The Type B2 inclusions have Al-rich and Al-poor populations, due to sector zoning.

higher An/Ge component ratios and are generally more $\mathrm{SiO}_{2}$-rich than Type B1 inclusions. The differences in bulk compositions can explain the basic differences between the compositions and zoning of melilite in Types B1 and B2 inclusions described above.

Because they are relatively $\mathrm{SiO}_{2}$-rich, liquids with the compositions of Type B2 inclusions have melilite appearance temperatures lower than those of Type B1s (Simon and Grossman, 2004). This is reflected in the higher minimum åkermanite contents of Type B2 melilite (Fig. 3),
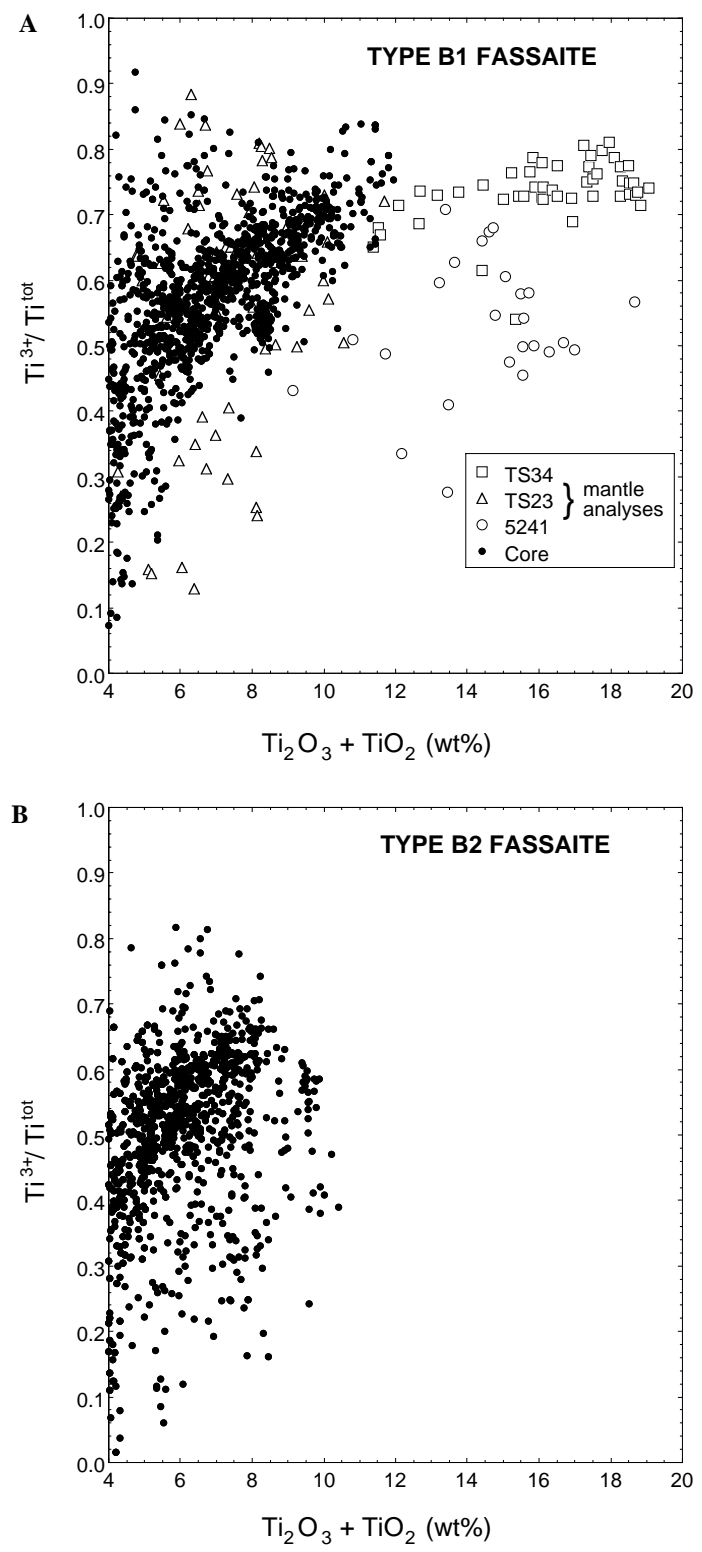

Fig. 8. Plots of $\mathrm{Ti}^{3+} / \mathrm{Ti}^{\text {tot }}$ vs. total Ti oxides in fassaite with $\mathrm{Ti}_{2} \mathrm{O}_{3}+\mathrm{TiO}_{2}$ $\geqslant 4 \mathrm{wt} \%$ for (A) three Type B1 and (B) three Type B2 inclusions. A stronger positive correlation is observed for the B1 data than for the B2 data.

and leads to shorter intervals of spinel + melilite crystallization prior to fassaite crystallization, in the $\mathrm{B} 2 \mathrm{~s}$ relative to the $\mathrm{B} 1 \mathrm{~s}$. Thus, it is probable that in $\mathrm{B} 2 \mathrm{~s}$, a higher proportion of the melilite cocrystallizes with fassaite than in B1s, in which much of the melilite should crystallize before fassaite. This could account for the variety of zoning patterns seen within each inclusion and the high proportions of asymmetrically zoned grains and reversely zoned grains in the B2s. With melilite crystallizing later in B2s than in B1s, at lower temperatures, and after more prior crystallization of fassaite, many grains would form from 

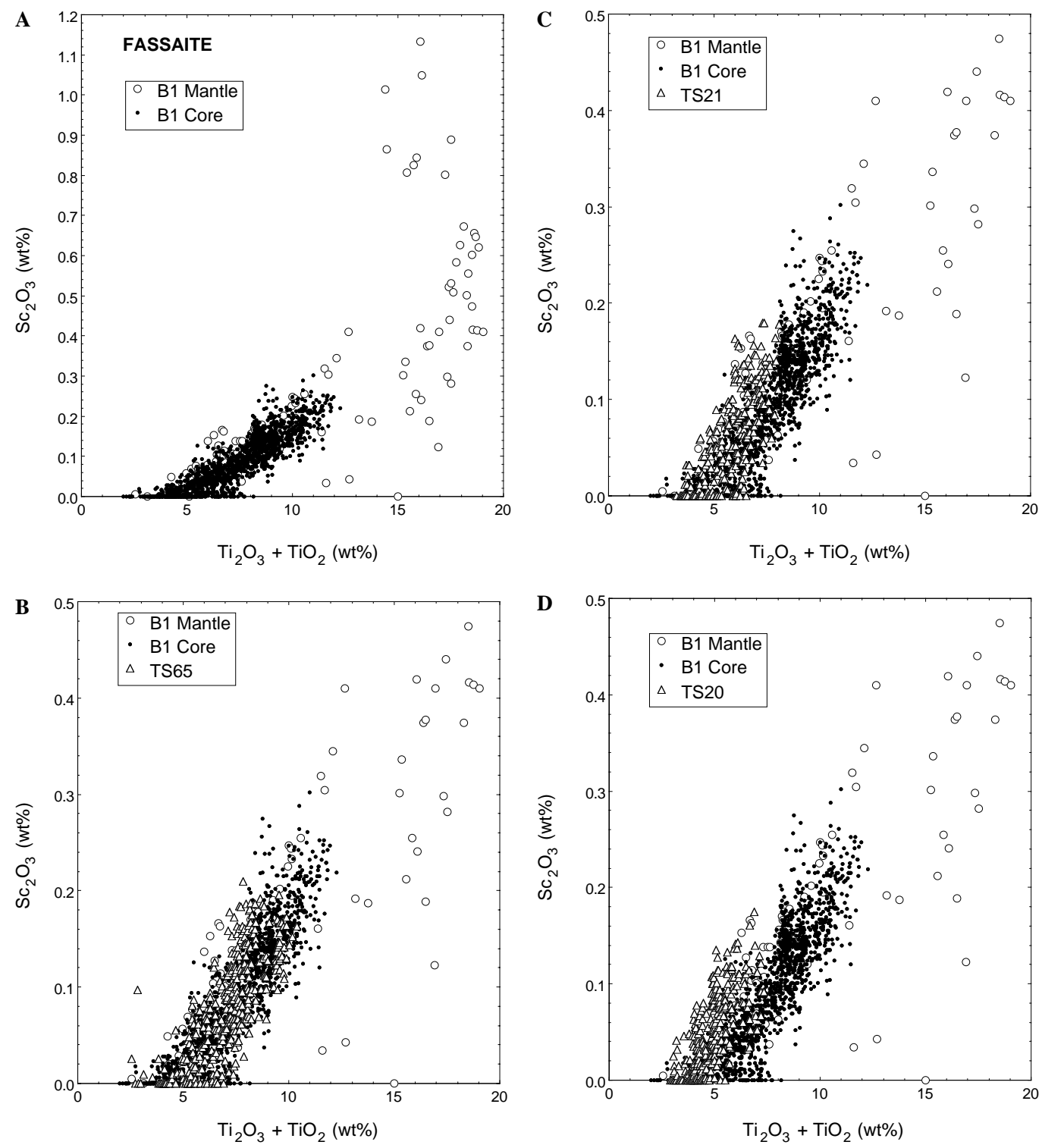

Fig. 9. Plots of $\mathrm{Sc}_{2} \mathrm{O}_{3}$ vs. $\mathrm{Ti}_{2} \mathrm{O}_{3}+\mathrm{TiO}_{2}$ contents in fassaite in three Type $\mathrm{B} 2$ inclusions compared to those of fassaite from Type $\mathrm{B} 1$ inclusions. (A) Abundances in cores and mantles of Type B1 inclusions. These data are plotted in (B-D) for comparison with Type B2 fassaite. (B) Fassaite from TS65. (C) Fassaite from TS21. (D) Fassaite from TS20. The degree of overlap between the B1 and B2 data decreases with increasing An/Ge component ratio of the B2 inclusion. TS65, with low An/Ge, shows the most overlap with the B1 data. TS20, with the highest An/Ge, shows the least. The composition range of Type $\mathrm{B} 1$ fassaite extends to higher $\mathrm{Sc}_{2} \mathrm{O}_{3}$ and $\mathrm{Ti}_{2} \mathrm{O}_{3}+\mathrm{TiO}_{2}$ contents than that of the Type $\mathrm{B} 2$ fassaite.

isolated pockets of melt, which evolved along different paths, leading to different zoning patterns. This would also likely lead to the formation of asymmetrically zoned grains. In such grains, one side of the crystal stopped growing before the other, presumably because only one side was in contact with liquid, consistent with its crystallization after solidification of a large fraction of the original liquid.

If this explanation is correct, $\AA \mathrm{k}$-rich, asymmetrically zoned melilite grains should be common in the cores of Type B1 inclusions, where late melilite cocrystallizes with other phases. As a test we analyzed 12 melilite grains in the cores of two B1 inclusions, and found that slightly less than one-half $(5 / 12)$ have asymmetrical zoning, just as we found for melilite in Type B2 inclusions (27 out of 56). Two of the Type B1 traverses are shown in Fig. 13, with traverses of two B1 mantle melilite grains for comparison. The mantle grains have much lower Åk contents and are asymmetrically zoned because one edge of the crystal was adjacent to the edge of the inclusion throughout its growth. The core grains are $\AA \mathrm{k}$-rich and are asymmetrically zoned because one edge of the grain came into contact with 

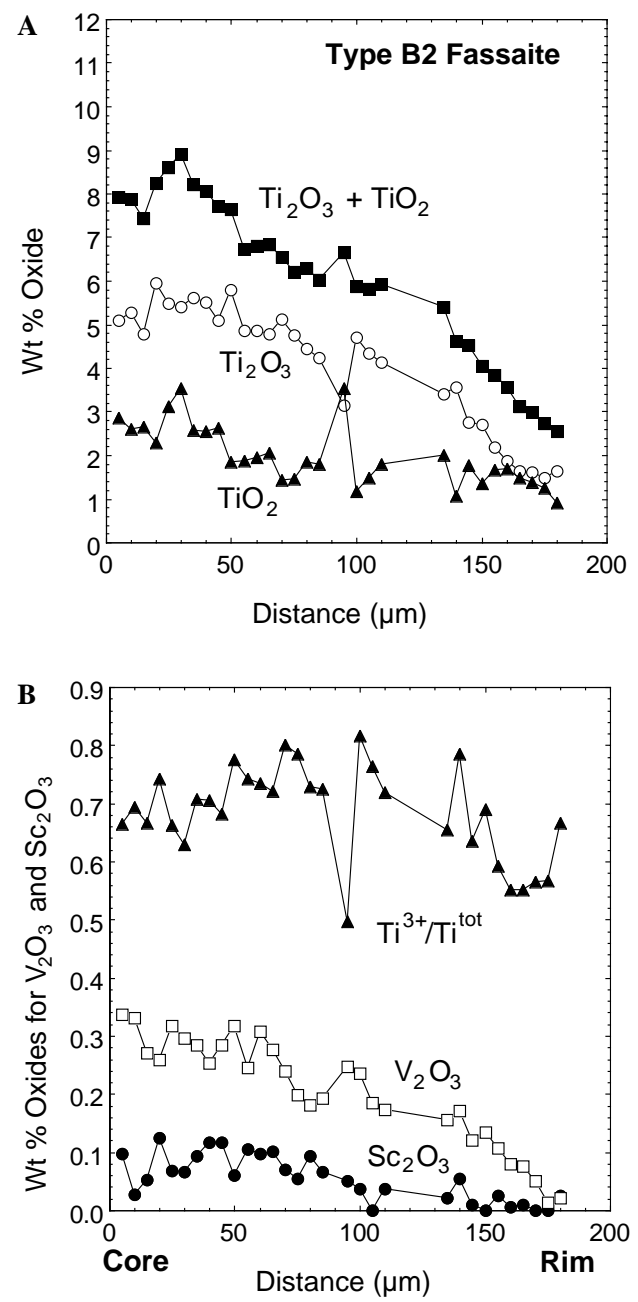

Fig. 10. Results of a core-rim electron microprobe traverse of a typical fassaite crystal in Type $\mathrm{B} 2$ inclusion TS65. (A) $\mathrm{Ti}_{2} \mathrm{O}_{3}+\mathrm{TiO}_{2}, \mathrm{Ti}_{2} \mathrm{O}_{3}$, and $\mathrm{TiO}_{2}$ contents as a function of distance from the core of the crystal. (B) $\mathrm{V}_{2} \mathrm{O}_{3}$ and $\mathrm{Sc}_{2} \mathrm{O}_{3}$ contents, and $\mathrm{Ti}^{3+} / \mathrm{Ti}^{\text {tot }}$, as a function of distance from the core of the crystal. Contents of the compatible oxides decrease from core to rim, but, unlike fassaite from Type B1 inclusions, $\mathrm{Ti}^{3+} / \mathrm{Ti}^{\text {tot }}\left[\mathrm{Ti}^{3+} /\right.$ $\left.\left(\mathrm{Ti}^{3+}+\mathrm{Ti}^{4+}\right)\right]$ does not decrease from core to rim.

another phase and stopped growing before the rest of the crystal did.

Earlier crystallization of melilite, with much less prior crystallization and cocrystallization of fassaite than B2s, would be inferred from the compositions of B1s and could account for the melilite-rich mantles of the latter, obviating the need for more complex models. It has been suggested, for example, that more rapid (Richter et al., 2002) or more extensive (Mendybaev et al., 2003) evaporative losses of $\mathrm{Mg}$ and $\mathrm{Si}$ than those experienced by Type B2 inclusions led to the formation of the melilite mantles of Type B1 inclusions. Our data show, however, that both Types B1 and B2 inclusions have anomalously gehlenitic melilite at their outermost edges. This suggests that both inclusion types experienced evaporation of small amounts of $\mathrm{Mg}$ and $\mathrm{Si}$ from their outer reaches. This induced melilite nucleation at the edges of both types of inclusions and makes it unlikely that different evaporation histories account for the presence or absence of a mantle in a Type $\mathrm{B}$ inclusion. It is more likely that the massiveness of the melilite mantles in the B1s is due to the relatively long temperature interval of melilite crystallization without simultaneous precipitation of fassaite or anorthite that would be expected from their relatively $\mathrm{Ca}$-rich, $\mathrm{Si}$-poor bulk compositions, as compared to those of the B2s. In contrast, because of the relatively Si-rich bulk compositions of Type B2 inclusions, less total melilite forms and less melilite precipitates before being joined by fassaite and anorthite, preventing the formation of a massive monomineralic mantle. Furthermore, the difference in bulk chemical composition between Types B1 and B2 inclusions appears not to be due to more extensive evaporation of $\mathrm{B} 1 \mathrm{~s}$ relative to $\mathrm{B} 2 \mathrm{~s}$, as the bulk Mg isotopic compositions of the two inclusion types overlap (Clayton et al., 1988; Simon et al., 2004).

Another effect of cocrystallization with fassaite is that, if fassaite dominates the crystallizing assemblage in the absence of anorthite, it will cause the $\mathrm{Al} / \mathrm{Mg}$ ratio of the residual liquid to increase, driving up the $\mathrm{Al} / \mathrm{Mg}$ ratio of cocrystallizing melilite, resulting in reverse zoning in the melilite (MacPherson et al., 1984). This effect is recorded as relatively thin, reversely zoned bands in the outer regions of those melilite crystals in Type B1 inclusions that were still growing when fassaite appeared. This effect has been reproduced experimentally (MacPherson et al., 1984). From the bulk compositions of inclusions and phase equilibria (Fig. 1), we can predict that, in Type B2 inclusions relative to $\mathrm{B} 1 \mathrm{~s}$, a higher proportion of the melilite will begin forming after fassaite has started to grow. This implies that a higher proportion of the melilite grains will have reverse zoning in Type B2 inclusions than in Type B1s and this is what is observed. We can also expect that a greater portion of each melilite grain that nucleated before fassaite would likely cocrystallize with fassaite prior to the appearance of anorthite. If this occurred, we would expect that the grains with reverse zoning would have relatively thicker reversely zoned bands, whose onset occurs closer to the crystal cores, in Type B2 than in Type B1 inclusions, and this is also observed.

Another notable feature of the melilite compositions is the similarity of Na-Åk relationships in Type B1 and Type $\mathrm{B} 2$ inclusions (Fig. 4). Although $\mathrm{Na}_{2} \mathrm{O}$ has been added to some melilite grains during secondary alteration, measurements of zoning within grains show strong correlations between $\mathrm{Na}_{2} \mathrm{O}$ and $\mathrm{A} k$ contents, which can be accounted for by fractional crystallization models (Beckett et al., 2000). Unlike Na-rich liquids, in which $\mathrm{D}$ does not vary strongly with $\AA \mathrm{k} / \mathrm{Ge}$ and is $<1$, in liquids with $<0.5 \mathrm{wt} \% \mathrm{Na}_{2} \mathrm{O}$, D varies from $\sim 0.5$ to $>1.5$ with increasing $\AA \mathrm{k} / \mathrm{Ge}$ (Beckett and Stolper, 2000). Therefore, the similarity of the B1 and $\mathrm{B} 2$ melilite trends indicates that the liquids from which they crystallized had similar $\mathrm{Na}_{2} \mathrm{O}$ contents. An early formed melilite mantle, therefore, was not required for 
A
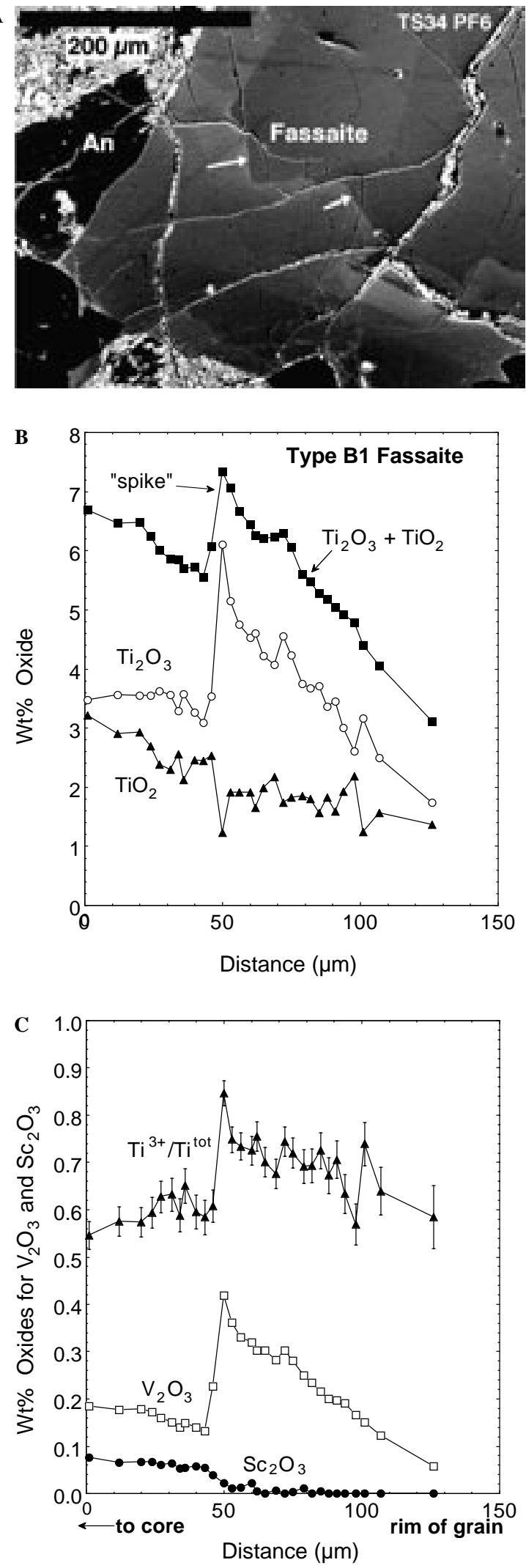

the retention of $\mathrm{Na}_{2} \mathrm{O}$ in molten Type B CAIs. Furthermore, if $\mathrm{Na}$ did not evaporate during the last melting event experienced by a given $\mathrm{CAI}$, then neither did $\mathrm{Mg}$ nor $\mathrm{Si}$, which are expected to have much lower vapor pressures than $\mathrm{Na}$ in CMAS liquids exposed to reducing gases. This implies that the bulk enrichments in the heavy isotopes of $\mathrm{Mg}$ and $\mathrm{Si}$ that are exhibited by CAIs (e.g., Clayton et al., 1988), if caused by evaporation, must have arisen during a heating event that preceded the one in which $\mathrm{Na}$ was retained. Why $\mathrm{Na}$ did not evaporate from the later, partially molten stage remains poorly understood.

The fact that many of the observed features of Type B inclusions are consistent with crystallization of liquids having the bulk compositions of the inclusions is also worth noting. One of the first steps in understanding the origin of an inclusion is to determine whether it is a gas-solid condensate or the product of crystallization of a liquid. One way to do this, in addition to petrographic observation, is to determine the bulk composition of an inclusion and then see if its properties are consistent with crystallization of a liquid of that composition. From the projection in Fig. 1 we can successfully predict the crystallization sequences of the inclusions as well as their relative melilite and fassaite abundances, and we find that melilite zoning trends can be understood in light of the range of bulk compositions.

\subsection{Inferences from fassaite}

Features of fassaite that are observed in one type of inclusion but not in the other yield some insight into the crystallization histories of the Type B inclusions, including possible effects of isolation of inclusion interiors by melilite mantles. The major differences we found between fassaite in B1s and B2s are: (1) the lack of zoning with respect to the $\mathrm{Ti}^{3+} / \mathrm{Ti}^{\text {tot }}$ ratio in fassaite in Type B2 inclusions; (2) the absence of Ti-V spikes in Type B2 inclusions; and (3) the common occurrence of sector-zoning in fassaite in Type B2 inclusions.

\subsubsection{Core-to-rim zoning}

Simon et al. (1991) showed that $\mathrm{Ti}^{3+}$ is strongly compatible in fassaite and has a crystal/liquid distribution coefficient greater than that of $\mathrm{Ti}^{4+}$. The $\mathrm{Ti}^{3+} / \mathrm{Ti}^{\text {tot }}$ ratio should therefore decrease from the core to the rim of a fassaite crystal formed from a liquid that was unable to reequilibrate with the surrounding, reducing, nebular gas.

Fig. 11. (A) Backscattered electron image of a fassaite crystal from Type B1 inclusion TS34 that exhibits a sharp Ti-, V-enrichment, or spike, seen here as a light-gray layer. The contact between inner (Ti-, V-poor) and outer (Ti-, V-rich) fassaite is indicated by arrows. (B and C) Results of an electron probe traverse across a Ti-, $\mathrm{V}$-spike in another fassaite crystal in TS34. Note that although $\mathrm{Sc}_{2} \mathrm{O}_{3}$ is also compatible in fassaite, its abundance does not increase at the spike. Uncertainties in $\mathrm{Ti}^{3+} / \mathrm{Ti}^{\text {tot }}$ were derived from counting statistics propagated through the calculation of the ratio. 

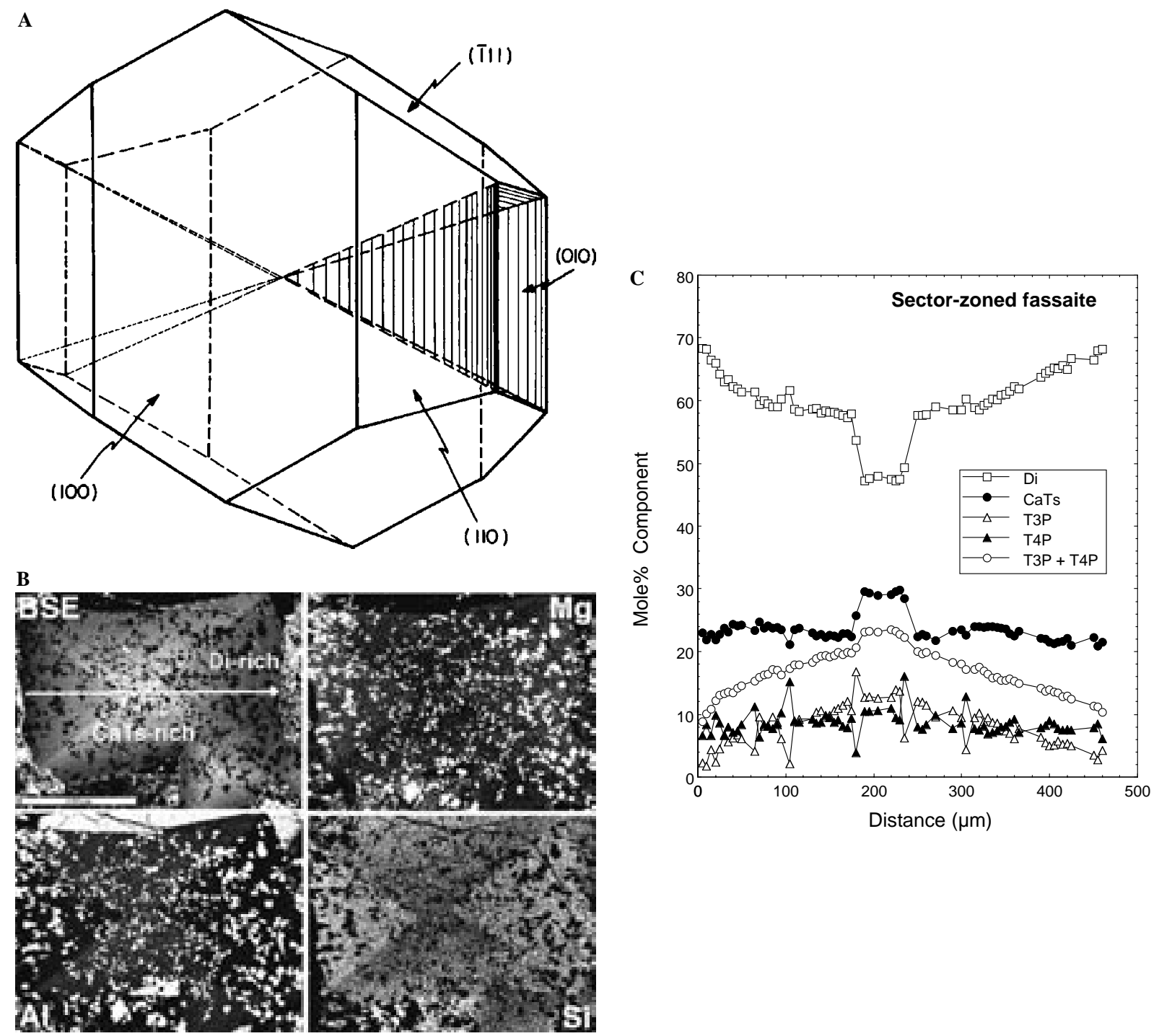

Fig. 12. (A) Sketch of a pyroxene crystal that would have four sectors. The pyramids represent the (010) sector. After Hollister and Gancarz (1971). (B) Backscattered electron image (BSE) and Mg, Al, and Si X-ray maps of a sector-zoned fassaite crystal in Type B2 inclusion TS21. The two dark sectors in the BSE and Al maps are enriched in the Di pyroxene component relative to the two light sectors, which are enriched in the CaTs and Ti-bearing components. The location and direction of an electron probe traverse across the grain are indicated by the arrowed line. (C) Results of an electron probe traverse across the sector-zoned fassaite crystal shown in (B), plotted as mole\% pyroxene components that are defined in the text.

Core-to-rim decreases in $\mathrm{Ti}^{3+} / \mathrm{Ti}^{\text {tot }}$ ratio are observed in fassaite in Type B1 inclusions but not in Type B2 inclusions (e.g., Fig. 10B). This implies that partially molten Type B2 inclusions maintained equilibrium with the nebular gas during fassaite crystallization and the interiors of B1s did not. An obvious explanation for this observation is that in Type B1s the melilite mantle was present before most of the fassaite crystallized and sealed off the interiors of the inclusions from the nebular gas. Fassaite crystallization depleted the residual melts in $\mathrm{Ti}^{3+}$, which was not replaced by reduction of $\mathrm{Ti}^{4+}$. In contrast, in Type B2s, the residual melt maintained communication with the nebular gas and its $\mathrm{Ti}^{3+} / \mathrm{Ti}^{\text {tot }}$ ratio did not tend to decrease; the ratio was held constant as $\mathrm{Ti}^{3+}$ that was taken up by fassaite was replenished by reduction of $\mathrm{Ti}^{4+}$. As crystallization proceeded, the total Ti content of the liquid decreased but its $\mathrm{Ti}^{3+} / \mathrm{Ti}^{\text {tot }}$ ratio stayed constant. Despite these different histories, the average $\mathrm{Ti}^{3+} / \mathrm{Ti}^{\text {tot }}$ ratio for fassaite in Type B2 inclusions is similar to that of the Type B1s, and their values indicate that both types formed under similar, highly reducing conditions, at an oxygen fugacity of $10^{-19.5 \pm 0.7}$ (Beckett, 1986), which is at least $0.6 \mathrm{log}$ units more reducing than a solar gas (Fedkin and Grossman, 2005). We know that at the start of crystallization, the melts from which Type B1 inclusions formed were strongly reduced, from the high $\mathrm{Ti}^{3+} / \mathrm{Ti}^{\text {tot }}$ ratios found in early-formed 

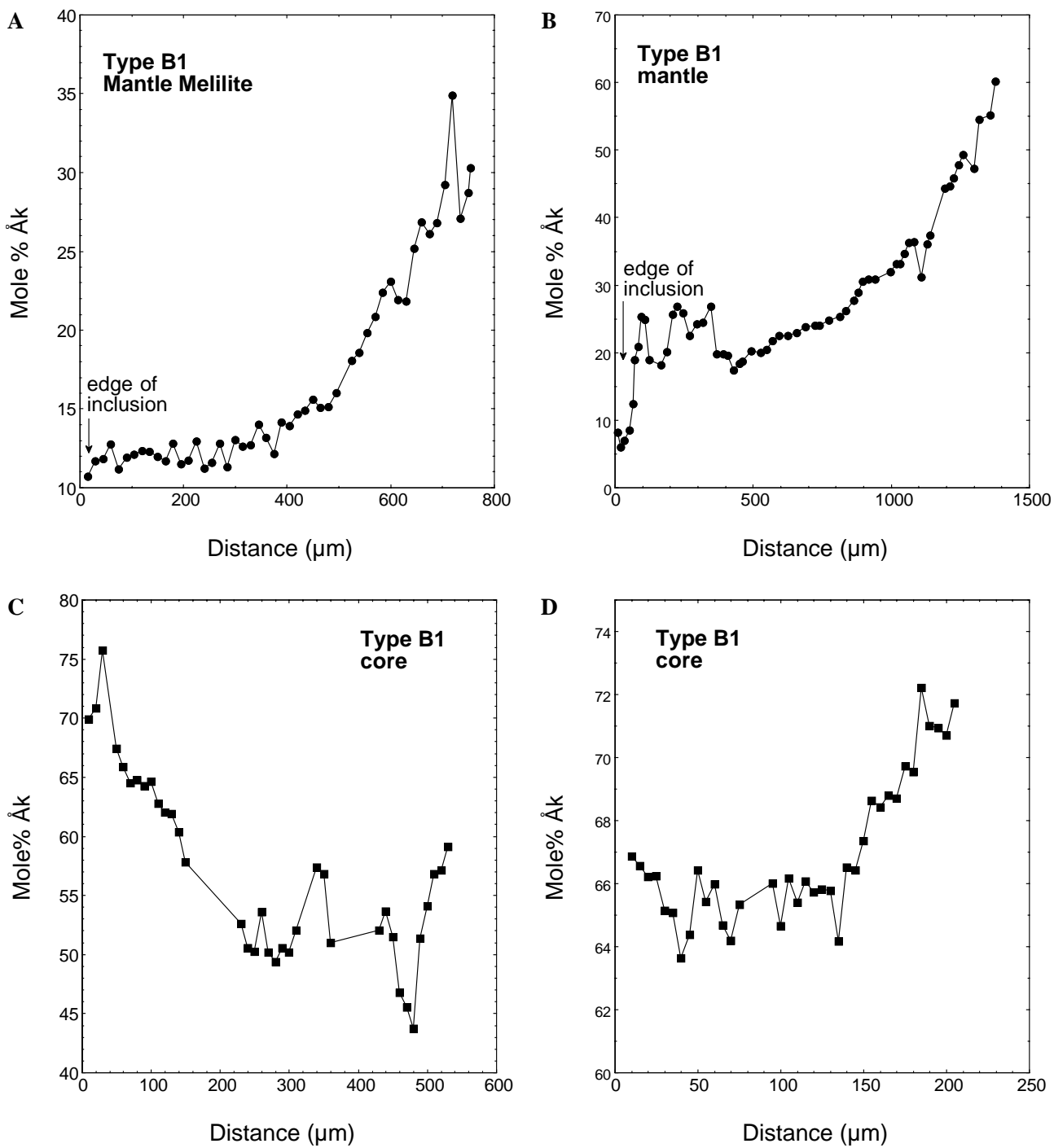

Fig. 13. Results of electron probe traverses across asymmetrically zoned melilite from Type B1 inclusions. (A and B) Along the long axes of mantle laths, from the inclusion edge inward toward the core. (C and D) From rim-to-rim across core grains.

fassaite in those inclusions. Grains that crystallized from early liquids trapped in the mantles, and the cores of large crystals are Ti-rich and typically have $\mathrm{Ti}^{3+} / \mathrm{Ti}^{\text {tot }}$ ratios $\sim 0.8$ (Simon et al., 1991). Much of the remaining fassaite has $\mathrm{Ti}^{3+} / \mathrm{Ti}^{\text {tot }}$ ratios between 0.5 and 0.7 (Fig. 8). These differences likely are due to partitioning and to equilibration among different phase assemblages during fractional crystallization rather than to changes in the ambient oxygen fugacity.

Isolation of inclusion interiors from the nebular gas by melilite mantles could have also set the stage for the formation of the Ti-V spikes seen in some fassaite grains in Type B1 inclusions. They do not appear to be the result of a change in the crystallizing assemblage during fractional crystallization. The most likely change would be the onset of anorthite crystallization. This would enrich the melt in components, including $\mathrm{Ti}$ and $\mathrm{V}$ oxides, that are incompatible in anorthite, and deplete the melt in components that are compatible in anorthite, such as Eu. Analyses show, however, that the contents of $\mathrm{Sc}_{2} \mathrm{O}_{3}$ (compatible in fassaite, incompatible in anorthite) do not change dramatically at the spikes, nor does the Sm/Eu ratio (Simon et al., 1992). This rules out anorthite crystallization as the cause of the spikes. As the only elements affected, Ti and V, are those with multiple oxidation states possible at the conditions under which refractory inclusions formed, a redox reaction is indicated.

The spikes clearly reflect late, sharp increases in the $\mathrm{Ti}^{3+} / \mathrm{Ti}^{\text {tot }}$ ratios of the liquids from which the fassaite was crystallizing. We do not yet know what oxidation state of $\mathrm{V}$ would be favored in fassaite, or whether a reduction event should enhance $\mathrm{V}$ contents in fassaite, and have 
undertaken an investigation (e.g., Sutton et al., 2002) to determine this. We do know that, if the late liquids in Type $\mathrm{B} 1$ inclusions had become relatively $\mathrm{Ti}^{3+}$-depleted due to fassaite fractionation and they were suddenly exposed to the nebular gas, their $\mathrm{Ti}^{3+} / \mathrm{Ti}^{\text {tot }}$ ratios would undergo sudden increases, which would be recorded in the growing fassaite. Isolation of inclusion interiors by the melilite mantles of Type B1 inclusions, followed by sudden exposure to the nebular gas through cracks, or possibly by inward diffusion of hydrogen, could therefore account for sharp increases in $\mathrm{Ti}^{3+} / \mathrm{Ti}^{\text {tot }}$ ratios and the spikes in $\mathrm{B} 1$ fassaite. Of course, if the liquid had maintained redox equilibrium throughout the crystallization interval, sudden reequilibration would not be possible. This is likely to have occurred during the formation of Type B2 inclusions, which have fassaite and anorthite, indicative of the presence of late liquids, near inclusion rims. Maintenance of redox equilibrium in B2s could therefore account for the absence of Ti-, V-rich spikes from fassaite in Type B2 inclusions, and, as discussed above, is consistent with the flat $\mathrm{Ti}^{3+} / \mathrm{Ti}^{\text {tot }}$ profiles seen in that fassaite. Evidence for communication between the melt and the reducing nebular gas in the absence of a melilite mantle makes it difficult to account for the retention of $\mathrm{Na}$ during crystallization of Type $\mathrm{B} 2$ inclusions in the nebula.

\subsubsection{Sector zoning}

It is possible for two faces of a crystal to grow simultaneously, with different compositions, from the same liquid. Different faces can have different partition coefficients for a given element because they expose different sets of crystallographic sites to the melt (Dowty, 1976), and this can lead to the development of sector zoning. If crystal growth is fast relative to diffusion within the lattice, sector zoning will be preserved. The common occurrence of sector zoning in Type B2 inclusions and its rarity in Type B1s may tell us something about the relative growth rates of fassaite in the two inclusion types.

Watson and Liang (1995) modeled the relationship between growth and diffusion for a growth layer thickness of $10 \AA$ and concluded that sector zoning will occur and be preserved in a crystal if the time scale for diffusion is one-half the growth time scale or less. We can use this relationship to estimate the minimum growth rate for preservation of sector zoning in fassaite. Recall that in CAIs the main differences between sectors are their CaTs and Di components. For CaTs-Di (AlAl/MgSi) interdiffusion at $1523 \mathrm{~K}, D=1.65 \times 10^{-13} \mathrm{~cm}^{2} \mathrm{~s}^{-1}$ (Grove and Wagner, 1993). Using this value, a half-width growth layer $(l)$ of $5 \AA$ (Watson and Liang, 1995), and the requirement that $V l / D=0.5$, where $V$ is the growth rate of the crystal, we obtain a growth rate of $1.65 \times 10^{-8} \mathrm{~m} \mathrm{~s}^{-1}$ or $1.65 \times 10^{-2}$ $\mu \mathrm{m} \mathrm{s}^{-1}\left(\sim 1 \mu \mathrm{m} \mathrm{min}{ }^{-1}\right)$. According to the model of Watson and Liang (1995), this would be the slowest rate at which fassaite could grow and retain Di-CaTs sector zoning, termed the "critical" growth rate. It is at the high end of the range of growth rates at which polyhedral (vs. hopper or dendritic) crystals formed, with supercooling of $25^{\circ} \mathrm{C}$, in experiments by Kouchi et al. (1983) on the CaM$\mathrm{gSi}_{2} \mathrm{O}_{6}-\mathrm{CaTiAl}_{2} \mathrm{O}_{6}\left(\mathrm{Di}_{4} \mathrm{~T}{ }_{4} \mathrm{P}\right)$ system. Sector zoning was also produced, however, in pyroxene crystals grown at less than one-tenth this rate, $1.2 \times 10^{-3} \mu_{\mathrm{m} \mathrm{s}}^{-1}$ (at $13{ }^{\circ} \mathrm{C}$ supercooling at $1310^{\circ} \mathrm{C}$ ), by Kouchi et al. (1983). The model of Watson and Liang (1995) would not predict sector zoning in crystals grown at this rate if the $D$ for CaTs-Di diffusion from Grove and Wagner (1993) is used. Noting this, Watson and Liang suggested, and we agree, that interdiffusion rates involved in the coupled substitution $\mathrm{Ti}^{4+}+2 \mathrm{Al}^{3+}$ $\Longleftrightarrow \mathrm{Mg}^{2+}+2 \mathrm{Si}^{4+}$ may be significantly lower than those in the Ti-free, CaTs-Di system considered by Grove and Wagner (1993). This is reasonable, as the $\mathrm{T}_{4} \mathrm{P}$-Di exchange involves substitutions among six cations, and CaTs-Di exchange involves just four. A lower $D$ would decrease the critical growth rate required for sector zoning. Measurement of the diffusivities in Ti-bearing, aluminous pyroxene is needed for better quantification of the growth rate needed to generate sector zoning in Type B inclusions.

The common occurrence of sector zoning in Type B2 inclusions and its rarity in B1s suggest that either lattice diffusion was slower in pyroxenes in B2s than in B1s or fassaite grew more rapidly in B2s than in B1s. Fassaite in Type B1s could not have had sector zoning that was erased by reheating because any event that was long and hot enough to do so would have completely homogenized the grains, and the observed core-rim variations would have been lost. Slower diffusion would be more probable if there was a reason to think that fassaite crystallized at lower temperatures in B2s than in B1s, but this is not the case. Experiments by Beckett (1986) show that fassaite crystallizes over similar temperature ranges in both inclusion types. Thus, it is likely that fassaite in B2s grew faster than the critical growth rate required for sector zoning, and that in $\mathrm{B} 1 \mathrm{~s}$ did not.

Type B2 inclusions may have cooled slightly more quickly than B1s, leading to a faster growth of fassaite, but they did not cool fast enough to cause grains to grow with skeletal morphologies. Another possible explanation for the inferred difference in pyroxene growth rates is that the bulk compositions of the Type $\mathrm{B} 2$ inclusions, being relatively $\mathrm{SiO}_{2}$-rich and having higher pyroxene components compared to the B1s, led to faster fassaite growth. In addition, with less prior melilite crystallization, higher proportions of liquid available at the start of fassaite crystallization could have facilitated transport of the necessary constituents within the melt to the growing crystals, enhancing crystal growth.

Since sector zoning can occur at quite modest growth rates, of the order of $10^{-3} \mu \mathrm{m} \mathrm{s}^{-1}$ (Kouchi et al., 1983), neither extreme degrees of supercooling nor particularly high growth or cooling rates need to be invoked for $\mathrm{B} 2 \mathrm{~s}$ relative to B1s. This is in agreement with experiments on Type B compositions, which suggest that the textures of natural inclusions are not consistent with formation from strongly supercooled melts (Stolper and Paque, 1986) or with cool- 
ing rates $>50{ }^{\circ} \mathrm{C} \mathrm{h}^{-1}$ (MacPherson et al., 1984). The results here are qualitatively consistent with faster pyroxene growth rates for B2s than for B1s, but there are many factors affecting these rates, such as the maximum temperature reached $\left(\mathrm{T}_{\max }\right)$, time spent at $\mathrm{T}_{\max }$, and kinetics, which prevent direct inference of cooling rates from crystal growth rates.

\section{Conclusions}

In this work, we have documented and interpreted mineral-chemical similarities and differences between the melilite and fassaite of Type B1 inclusions and that in Type B2 inclusions. Similarities include:

1. Maximum $\AA \mathrm{k}$ content of melilite is $\sim 75 \mathrm{~mol} \%$;

2. positive correlation between $\AA \mathrm{k}$ and $\mathrm{Na}_{2} \mathrm{O}$ contents;

3. reversely zoned melilite is present, though somewhat more common in $\mathrm{B} 2 \mathrm{~s}$ than in $\mathrm{B} 1 \mathrm{~s}$; and

4. most fassaite has $\mathrm{Ti}^{3+} / \mathrm{Ti}^{\text {tot }}$ between 0.5 and 0.7 .

Differences include:

1. Melilite is commonly Åk-rich and asymmetrically zoned in Type B2s;

2. the reversely zoned portions of melilite crystals are thicker in Type B2s than in B1s;

3. in B2s, fassaite is not concentrically zoned with respect to $\mathrm{Ti}^{3+} / \mathrm{Ti}^{\text {tot }}$ ratios;

4. in B2s, sharp Ti-, V-enrichment fronts are not observed in fassaite; and

5. in B2s, fassaite is commonly sector-zoned with respect to the Di and CaTs components.

The common occurrence of asymmetrically zoned melilite grains and of grains with reversely zoned outer regions, and the greater thicknesses of the reversely zoned portions of melilite crystals in Type B2 inclusions relative to Type B1s are consistent with later crystallization of melilite, and more extensive cocrystallization with fassaite, in B2s than in B1s, which would be expected based on their bulk compositions. The similarity of the $\mathrm{Na}_{2} \mathrm{O}-\mathrm{A} \mathrm{k}$ relationships in Type $\mathrm{B} 2 \mathrm{~s}$ to that observed in $\mathrm{B} 1 \mathrm{~s}$ indicates that sealing off of inclusion interiors from the nebular gas by a melilite mantle was not required for retention of $\mathrm{Na}$ during crystallization. The similarity of the $\mathrm{Ti}^{3+} / \mathrm{Ti}^{\text {tot }}$ ratios in fassaite in $\mathrm{B} 1 \mathrm{~s}$ and $\mathrm{B} 2 \mathrm{~s}$ indicates crystallization under similar, highly reducing conditions. The lack of crystal zoning with respect to $\mathrm{Ti}^{3+} / \mathrm{Ti}^{\text {tot }}$ ratios and the absence of Ti-, V-spikes contrast with observations of Type B1 inclusions, and are features of B2 fassaite that are consistent with maintenance of gas-liquid equilibrium during fassaite crystallization. The near ubiquity of sector zoning in fassaite in Type B2 inclusions and its virtual absence from B1s suggest that fassaite grew faster in B2s than in B1s. This could be due to slightly faster cooling of B2s, higher normative pyroxene contents in the melts, and/or less crystallization prior to the appearance of fassaite, easing transport of components needed for fassaite growth, in $\mathrm{B} 2 \mathrm{~s}$ relative to $\mathrm{B} 1 \mathrm{~s}$.

\section{Acknowledgments}

This work was supported by the National Aeronautics and Space Administration (NASA) through Grants NAG5-11588 and NNG05GG00G, and funding is gratefully acknowledged. Comments by S. Russell, H. Connolly, Jr., and J. Paque led to improvements in the data displays and in the text.

Associate editor: Sara S. Russell

\section{References}

Beckett, J.R., 1986. The origin of calcium-, aluminum-rich inclusions from carbonaceous chondrites: an experimental study. Ph.D. thesis, University of Chicago.

Beckett, J.R., Stolper, E., 2000. The partitioning of Na between melilite and liquid: Part I. The role of crystal chemistry and liquid composition. Geochim. Cosmochim. Acta 64, 2509-2517.

Beckett, J.R., Paque, J.M., Stolper, E., 1999. The use of melilite compositions to constrain the thermal history and liquid line of descent of Type B CAIs. Lunar Planet. Sci. XXX. Lunar Planet. Inst., Houston. \#1920 (abstract).

Beckett, J.R., Simon, S.B., Stolper, E., 2000. The partitioning of Na between melilite and liquid: Part II. Application to Type B inclusions from carbonaceous chondrites. Geochim. Cosmochim. Acta 64, 25192534.

Brearley, A.J., Jones, R.H., 1998. Chondritic meteorites. In: Papike, J.J. (Ed.), Planetary Materials. Mineralogical Soc. Amer., Washington, DC, pp. 313-398.

Clayton, R.N., Hinton, R.W., Davis, A.M., 1988. Isotopic variations in the rock-forming elements in meteorites. Phil. Trans. R. Soc. Lond. A 325, 483-501.

Davis, A.M., Simon, S.B., Grossman, L., 1992. Melilite composition trends during crystallization of Allende Type B1 refractory inclusion melts. Lunar Planet. Sci. XXIII, 281-282. Lunar Planet. Inst., Houston. (abstract).

Dowty, E., 1976. Crystal structure and crystal growth: II. Sector zoning in minerals. Am. Min. 61, 460-469.

Dowty, E., Clark, J.R., 1973. Crystal structure refinement and optical properties of a $\mathrm{Ti}^{3+}$ fassaite from the Allende meteorite. Am. Min. 58, 230-242.

Grove, T.L., Wagner, T.P., 1993. Is adiabatic melting of oceanic mantle a disequilibrium process? Constraints from element diffusion rates in high-Ca pyroxene. Eos 74, 284 (abstract).

Fedkin, A.V., Grossman, L., 2005. The fayalite content of chondritic olivine: Obstacle to understanding the condensation of rocky material. In Meteorites and the Early Solar System II, D. Lauretta, L.A. Leshin, H.Y. McSween, Jr. (Eds.). University of Arizona Press, Tucson, and the Lunar and Planetary Inst., Houston (in press).

Hollister, L.S., Gancarz, A.J., 1971. Compositional sector-zoning in clinopyroxene from the Narce area, Italy. Am. Min. 56, 959-979.

Kouchi, A., Sugawara, Y., Kashima, K., Sunagawa, I., 1983. Laboratory growth of sector zoned clinopyroxenes in the system $\mathrm{CaMgSi}_{2} \mathrm{O}_{6}$ $\mathrm{CaTiAl}_{2} \mathrm{O}_{6}$. Contrib. Mineral. Petrol. 83, 177-184.

MacPherson, G.J., Grossman, L., Allen, J.M., Beckett, J.R., 1981. Origin of rims on coarse-grained inclusions in the Allende meteorite. Proc. Lunar Planet. Sci. Conf. 12, 1079-1091.

MacPherson, G.J., Paque, J., Stolper, E., Grossman, L., 1984. The origin and significance of reverse zoning in melilite from Allende Type B inclusions. J. Geol. 92, 289-305. 
MacPherson, G.J., Crozaz, G., Lundberg, L.L., 1989. The evolution of a complex type B Allende inclusion: An ion microprobe trace element study. Geochim. Cosmochim. Acta 53, 2416-2427.

Marvin, U.B., Wood, J.A., Dickey Jr., J.S., 1970. Ca-Al rich phases in the Allende meteorite. Earth Planet. Sci. Lett. 7, 346-350.

Mendybaev, R.A., Richter, F.M., Davis, A.M., 2003. Formation of the melilite mantle of the Type B1 CAIs: Experimental simulations. Lunar Planet. Sci. XXXIV. Lunar Planet. Inst., Houston. \#2062 (abstract).

Pouchou, J.L., Pichoir, F., 1984. A new model for quantitative x-ray microanalysis. Part I: application to the analysis of homogeneous samples. Rech. Aerosp. 1984-1993, 13-38.

Richter, F.M., Davis, A.M., Mendybaev, R.A., 2002. How the Type B1 CAIs got their melilite mantles. Lunar Planet. Sci. XXXIII. Lunar Planet. Inst., Houston. \#1901 (abstract).

Simon, S.B., Grossman, L., 1991. Profiles of $\mathrm{Ti}^{3+} / \mathrm{Ti}^{4+}$ ratios in fassaite in Allende refractory inclusions (abstract). Meteoritics 26, 395.

Simon, S.B., Grossman, L., 2003a. Insights into the formation of Type B2 refractory inclusions. Lunar Planet. Sci. XXXIV. Lunar Planet. Inst. Houston. \#1796 (abstract).

Simon, S.B., Grossman, L., 2003b. Composition and zoning of fassaite in type B2 refractory inclusions. Geochim. Cosmochim. Acta 67, A437 (abstract).

Simon, S.B., Grossman, L., 2004. A preferred method for the determination of bulk compositions of coarse-grained refractory inclusions and some implications of the results. Geochim. Cosmochim. Acta $\mathbf{6 8}$, 4237-4248.

Simon, S.B., Grossman, L., Davis, A.M., 1991. Fassaite composition trends during crystallization of Allende Type B refractory inclusions. Geochim. Cosmochim. Acta 55, 2635-2655.

Simon, S.B., Davis, A.M., Grossman, L., 1992. Evidence for changes in redox state during crystallization of Allende type B1 inclusions. Meteoritics 27, 289-290 (abstract).
Simon, S.B., Davis, A.M., Grossman, L., 1999. Origin of compact Type A refractory inclusions from $\mathrm{CV} 3$ carbonaceous chondrites. Geochim. Cosmochim. Acta 63, 1233-1248.

Simon, S.B., Grossman, L., Hutcheon, I.D., Williams, R.W., Galy, A., Fedkin, A.V., Clayton, R.N., Mayeda, T.K., 2004. Determination of primordial refractory inclusion compositions. Lunar Planet. Sci. XXXV. Lunar Planet. Inst., Houston. \#1684 (abstract).

Simon, S.B., Grossman, L., Davis, A.M., 2005. A unique Type B inclusion from Allende with evidence for multiple stages of melting. Meteorit. Planet. Sci. 40, 461-475.

Stolper, E., 1982. Crystallization sequences of Ca-Al-rich inclusions from Allende: An experimental study. Geochim. Cosmochim. Acta 46, 2159 2180.

Stolper, E., Paque, J.M., 1986. Crystallization sequences of Ca-Al-rich inclusions from Allende: The effects of cooling rate and maximum temperature. Geochim. Cosmochim. Acta 50, 1785-1806.

Sutton, S.R., Simon, S., Grossman, L., Delaney, J.S., Beckett, J., Newville, M., Eng, P., Rivers, M., 2002. Evidence for divalent vanadium in Allende CAI fassaite and implications for formation conditions. Lunar Planet. Sci. XXXIII. Lunar Planet. Inst., Houston. \#1907 (abstract).

Wark, D.A., Lovering, J.F., 1977. Marker events in the early evolution of the solar system: Evidence from rims on $\mathrm{Ca}-\mathrm{Al}$-rich inclusions in carbonaceous chondrites. Proc. Lunar Sci. Conf. 8, 95-112.

Wark, D.A., Lovering, J.F., 1982. The nature and origin of type B1 and B2 Ca-Al-rich inclusions in the Allende meteorite. Geochim. Cosmochim. Acta 46, 2581-2594.

Wark, D.A., Shelley, J.M.G., O’Neill, H., 2005. The first step in CAI rim formation: Flash heating or subsolidus evaporation? Lunar Planet. Sci. XXXVI. Lunar Planet. Inst., Houston. \#1643 (abstract).

Watson, E.B., Liang, Y., 1995. A simple model for sector zoning in slowly grown crystals: Implications for growth rate and lattice diffusion, with emphasis on accessory minerals in crustal rocks. Am. Min. 80, 11791187. 